\title{
Experimental Analysis and Optimization to Maximize Ultimate Tensile Strength and Ultimate Elongation of Friction Stir Welded AA6082 Aluminum Alloy
}

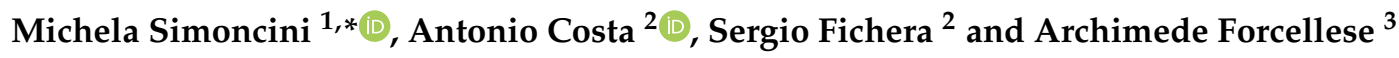 \\ 1 Faculty of Engineering, eCampus University, Via Isimbardi, 10-22060 Novedrate, Italy \\ 2 Faculty of Engineering, University of Catania, DICAR, Via Santa Sofia, 64-95125 Catania, Italy; \\ antonio.costa@dii.unict.it (A.C.); sfichera@diim.unict.it (S.F.) \\ 3 Faculty of Engineering, Polytechnic University of Marche, DIISM, Via Brecce Bianche, 12-60131 Ancona, Italy; \\ a.forcellese@staff.univpm.it \\ * Correspondence: michela.simoncini@uniecampus.it; Tel.: +39-071-220-4443
}

check for updates

Citation: Simoncini, M.; Costa, A.; Fichera, S.; Forcellese, A.

Experimental Analysis and Optimization to Maximize Ultimate Tensile Strength and Ultimate Elongation of Friction Stir Welded AA6082 Aluminum Alloy. Metals 2021, 11, 69. https://doi.org/ $10.3390 /$ met11010069

Received: 30 November 2020 Accepted: 28 December 2020 Published: 31 December 2020

Publisher's Note: MDPI stays neutral with regard to jurisdictional clai$\mathrm{ms}$ in published maps and institutional affiliations.

Copyright: (C) 2020 by the authors. Licensee MDPI, Basel, Switzerland. This article is an open access article distributed under the terms and conditions of the Creative Commons Attribution (CC BY) license (https:// creativecommons.org/licenses/by/ $4.0 /)$.

\begin{abstract}
Friction stir welding (FSW) is a well-established welding technique, which allows joining abutting surfaces by generating heating through a rotating and translating tool specifically shaped. Differently from the conventional techniques, continuous welding processes can be executed by FSW, thus supporting the economy of scales objectives. This paper deals with the selection of the optimal process parameters for the FSW of the AA6082 aluminum alloy. Three welding parameters, namely tool plunging, rotational speed and welding speed, have been handled as independent variables for developing two mathematical models by means of a non-linear regression-based approach, with the aim of predicting both ultimate tensile strength and ultimate elongation of the welded joints. A set of additional experimental tests has been used to validate the mentioned metamodels and finally three different metaheuristic algorithms have been implemented for selecting the best process parameters able to maximize the aforementioned mechanical properties. A comparison analysis based on further experimental tests confirmed the accuracy of the predicting metamodels and the quality of solutions yielded by the proposed optimization approaches.
\end{abstract}

Keywords: friction stir welding; aluminum alloy; regression; response surface methodology; harmony search; DOE

\section{Introduction}

Friction stir welding (FSW) has been proving to be an effective and efficient solid-state welding technique for joining materials difficult to be welded by means of conventional technologies, such as aluminum, magnesium and copper alloys, also including polymers, leading to a series of advantages with respect to the fusion welding techniques [1-6]. Notably, common defects of the conventional welding processes, such as solidification cracking, oxidation, distortion and porosity, do not occur in the FSW applications [2,7].

Several parameters, such as tool rotational speed, welding speed, axial force, tool pin shape, tool plunging, dwelling time, etc., can affect the mechanical properties of friction stir welded joints. Simoncini and Forcellese [8] studied the effect of the ratio between rotational and welding speeds on the ultimate tensile strength (UTS) and ultimate elongation (UE) of friction stir welded joints of similar and dissimilar joints in AA5754 and AZ31 alloys, using different tool configurations. They observed that, for similar joints, UTS and UE increase as the ratio grows to a peak value, and then they decrease as the ratio further rises. The mechanical properties of the joints were evaluated versus the process parameters and the relationships among the UTS, UE and the vertical force were defined. As for AA5754AZ31 dissimilar joints, regardless of the process parameters, the friction stir welded joints exhibit UTS and UE values significantly lower than the ones related to the parent materials. 
In addition, further analyses revealed as the pinless tool process leads to highest UTS and UE values if compared to those arising from the process employing a pin tool. Another research studied the effect of rotational speed, welding speed, dwelling time on UTS and UE values, vertical force and temperature on the FSW of AZ31 magnesium alloy $[9,10]$. Among the main findings, the highest values of UTS and UE are connected to both a lower vertical force and higher temperature values.

In order to assure the best mechanical properties of the welded products, a proper optimization approach is required to select the best process parameters. Different modeling and optimization techniques such as response surface methodology (RSM), neural network-based approaches and fuzzy logic-based techniques have been adopted by literature so far. Table 1 shows the main literary contributions proposed in the last decade about prediction and optimization of the mechanical properties of joints yielded by the friction stir welding technique. Notably, such a table represents an overview of the leading research works coping with friction stir welding of aluminum alloys. The list of notations can be found in Abbreviations. The "response" classification criterion in Table 1 focuses on the mechanical properties investigated by the mentioned contributions, while disregarding any information about corrosion and microstructural implications. Looking at the prediction model criterion, most papers used the RSM approach for modeling the friction stir welding process and selecting the optimal process parameters. RSM developed by Box and Wilson [11] is a collection of statistical and mathematical methods for modeling and optimizing engineering problems. The objective of such methodology is to optimize the response surface function depending on a series of independent variable, i.e., the process parameters. The main step to follow for implementing the response surface method are: (i) generating a design of experiments (DOE) to adequately collect a set of measures of the process under investigation; (ii) formalizing a mathematical model based on a second-order polynomial surface that adequately fits the experimental results; (iii) selecting the best parameters able to optimize one or more responses and (iv) analyzing interactions between input variables and responses through a series of contour/surface plots. A few contributions employed the artificial neural network (ANN) approach to model the mechanical properties of the welding joints for a single aluminum alloy [12-14] or dissimilar materials [15,16]. As an alternative approach, the adaptive neuro-fuzzy inference system called ANFIS, that is a kind of artificial neural network based on Takagi-Sugeno fuzzy inference system, was used to model the tensile strength of friction stir welded joints of AA7075, AA6061-T6 and AA2219-T87 aluminum alloys [17-19]. Recently, Shanavas and Dhas [20] used a fuzzy-logic based technique to predict both ultimate tensile strength and yield strength (YS) of AA5052H32 specimens derived by a FSW process. Under the material viewpoint, mechanical properties of AA6061 and AA7075 aluminum alloys were the most investigated; in some cases, friction stir welded joints of dissimilar materials have been studied [15,16,21-24]. Looking at the classification criterion denoted as "parameters", in most cases the tool rotational speed $(\omega)$, the welding speed $(v)$ and the downward axial force $(F)$ result the main variables involved in the process analyses [12,16-19,22,23,25-35]. Another finding from Table 1 is that a number of three or four input variables is usually considered as the most suitable number of parameters to predict the mechanical properties of friction stir welded joints. However, the tool shoulder diameter $(D)$ or the tool profile $\left(T_{p}\right)$ appear as further interesting input variables to be included in the process modeling $[17,20,21,25,26,32-41]$. The influence of process parameters on the mechanical properties of friction stir welded joints is usually investigated in terms of ultimate tensile strength, as demonstrated by the multitude of marks on the UTS column of Table 1. Secondarily, the yield strength and the ductility are two additional responses frequently analyzed by literature. A few papers also considered the hardness $(\mathrm{H})$ of the welded joint as a response variable $[13,15,31,33,34,38]$ and just one contribution analyzed the maximum temperature $\left(T_{m}\right)$ as an output variable to be minimized [39]. 
Table 1. Overview of the literature on friction stir welding (FSW).

\begin{tabular}{|c|c|c|c|c|c|c|c|c|c|c|c|c|c|c|c|c|c|c|c|c|c|}
\hline \multirow{2}{*}{ id } & \multirow{2}{*}{ Reference } & \multirow{2}{*}{ Material } & \multicolumn{9}{|c|}{ Process Parameters } & \multicolumn{5}{|c|}{ Response } & \multicolumn{4}{|c|}{ Prediction Model } & \multirow{2}{*}{ Optim. } \\
\hline & & & $\omega$ & $\mathbf{v}$ & $\mathbf{F}$ & D & $\mathrm{T}$ & $T_{p}$ & $\mathbf{P}$ & $\mathbf{R}$ & $\mathbf{H}$ & UTS & YS & UE & $\mathbf{H}$ & $\mathrm{T}_{\mathrm{m}}$ & RSM/NLR & ANN & ANFIS & FLT & \\
\hline 1 & Lakshminarayanan et al. [12] & AA7039 & $x$ & $x$ & $\mathrm{x}$ & & & & & & & $\mathrm{x}$ & & & & & $\mathrm{x}$ & $\mathrm{x}$ & & & - \\
\hline 2 & Babu et al. [13] & AA2219 & $x$ & $x$ & & & $x$ & & & & & $x$ & & & $x$ & & & $x$ & & & GA \\
\hline 3 & Shojaeefard et al. [15] & AA7075-O/ AA5083-O & $x$ & $x$ & & & & & & & & $x$ & & & $x$ & & & $x$ & & & PSO \\
\hline 4 & Babajanzade Roshan et al. [17] & AA7075 & $x$ & $x$ & $x$ & & & $x$ & & & & $x$ & $x$ & & & & & & $\mathrm{x}$ & & SA \\
\hline 5 & Dewan et al. [18] & AA6061-T6 & $x$ & $x$ & $x$ & & & & & & & $\mathrm{x}$ & & & & & & & $x$ & & - \\
\hline 6 & Shanavas and Dhas [20] & AA5052-H32 & $x$ & $x$ & & $x$ & & $x$ & & & & $\mathrm{x}$ & $x$ & & & & & & & $x$ & - \\
\hline 7 & Sundaram and Murugan [21] & Dissimilar & $x$ & $x$ & $x$ & & & $x$ & & & & $x$ & & & & & $x$ & & & & - \\
\hline 8 & Elatharasan and Kumar [22] & AA6061-T6/AA7075-T6 & $\mathrm{x}$ & $x$ & $x$ & & & & & & & $x$ & $x$ & $x$ & & & $x$ & & & & DF \\
\hline 9 & Padmanaban et al. [23] & AA2024/AA7075 & $x$ & $x$ & & & & & & & & $\hat{x}$ & & & & & $\hat{x}$ & & & & - \\
\hline 10 & Palanivel et al. [24] & AA6351/AA5083 & $x$ & $x$ & & & & $x$ & & & & $x$ & & & & & $x$ & & & & - \\
\hline 11 & Rajakumar et al. [34] & AA6061-T6 & $x$ & $x$ & $x$ & $x$ & & & $x$ & & $x$ & $x$ & & & $x$ & & $\mathrm{x}$ & & & & DF \\
\hline 12 & Elangovan et al. [35] & AA6061 & $x$ & $x$ & $\mathrm{x}$ & & & $x$ & & & & $x$ & & & & & $x$ & & & & HJ-PS \\
\hline 13 & Elangovan et al. [25] & AA2219 & $x$ & $x$ & $\mathrm{x}$ & & & $x$ & & & & $x$ & & & & & $x$ & & & & - \\
\hline 14 & Elangovan et al. [26] & AA6061 & $x$ & $x$ & $\mathrm{x}$ & & & $x$ & & & & $x$ & & & & & $x$ & & & & DF \\
\hline 15 & Elatharasan and Kumar [27] & AA6061-T6 & $\mathrm{x}$ & $\mathrm{x}$ & $\mathrm{x}$ & & & & & & & $\mathrm{x}$ & $x$ & & & & $\mathrm{x}$ & & & & - \\
\hline 16 & Heidarzadeh et al. [28] & AA6061-T4 & $x$ & $x$ & $x$ & & & & & & & $x$ & $x$ & & & & $x$ & & & & DF \\
\hline 17 & Kalaiselvan and Murugan [29] & AA6061-B4C & $\mathrm{x}$ & $x$ & $\mathrm{x}$ & & & & & $x$ & & $x$ & & & & & $x$ & & & & GRG \\
\hline 19 & $\begin{array}{c}\text { Rajakumar and } \\
\text { Balasubramanian [31] }\end{array}$ & $\begin{array}{l}\text { AA1100, AA2219, AA2024, } \\
\text { AA6061, AA7039, AA7075 }\end{array}$ & $x$ & $x$ & $\mathrm{x}$ & & & & & & & $\mathrm{x}$ & & $x$ & $\mathrm{x}$ & & $\mathrm{x}$ & & & & $\mathrm{DF}$ \\
\hline 20 & Rajakumar et al. [32] & AA7075-T6 & $x$ & $x$ & $x$ & $x$ & & & $x$ & & $x$ & $\mathrm{x}$ & & & & & $x$ & & & & - \\
\hline 21 & Babu et al. [33] & AA5059 & $x$ & $x$ & $x$ & & & & & & & $\mathrm{x}$ & & & $x$ & & $\mathrm{x}$ & & & & DF \\
\hline 22 & Rajakumar et al. [41] & AA7075-T6 & $\mathrm{x}$ & $x$ & $\mathrm{x}$ & $x$ & & & $x$ & & $x$ & $\mathrm{x}$ & & & & & $x$ & & & & - \\
\hline 23 & Ghaffarpour et al. [36] & 5083-H12, 6061-T6 & $x$ & $x$ & & $x$ & & & $x$ & & & & $x$ & $x$ & & & $\mathrm{x}$ & & & & - \\
\hline 24 & Boulahem et al. [37] & AA2024-T3 & $\mathrm{x}$ & $x$ & & $x$ & & & & & & $x$ & & & & & $x$ & & & & - \\
\hline 25 & Farzadi et al. [40] & AA7075-T6 & $\mathrm{x}$ & $x$ & & $x$ & & & $x$ & & & $\mathrm{x}$ & & & & & $\mathrm{x}$ & & & & DF \\
\hline 26 & Safeen et al. [38] & AA6061-T6 & $\mathrm{x}$ & $x$ & & $x$ & & $x$ & & & & $x$ & & & $x$ & & $x$ & & & & DF \\
\hline 27 & Liao and Daftardar [39] & AA2195-T8 & $x$ & $x$ & & $x$ & & & & & & & & & & $x$ & $x$ & & & & $\begin{array}{c}\text { GA, DE, } \\
\mathrm{ACO}, \\
\mathrm{PSO}, \mathrm{HS}\end{array}$ \\
\hline 28 & Abd Elaziz et al. 2020 [16] & AA2024/AA5083 & $x$ & $x$ & $x$ & & & & $x$ & & & $x$ & & $x$ & & & & $\mathrm{x}$ & & & - \\
\hline 29 & Shehabeldeen et al. 2020 [14] & AA6061-T6 & $x$ & $x$ & & & $x$ & & $x$ & & & $\mathrm{x}$ & & & & & & $\mathrm{x}$ & & & - \\
\hline 30 & Shehabeldeen et al. 2019 [19] & AA2219-T87 & $\mathrm{x}$ & $\mathrm{x}$ & $x$ & & & & & & & $\mathrm{x}$ & & & & & & & $x$ & & - \\
\hline
\end{tabular}


In general, whatever be the manufacturing process, one of the main challenges for an engineer or a machine operator is to select the process parameters able to assure both expected mechanical properties and technological requirements of the manufactured product. As for the welding process, selecting the optimal process parameters for a new welded product may be a time-consuming task, often based on a trial-and-error approach. As shown by Table 1, several authors just investigate how the input variables affect the responses under investigation (see papers with no data in the last column). However, a natural consequence of a mathematical modeling consists of the optimization phase, which would enable the selection of the best parameters to maximize/minimize a certain response variable. To this end, different optimization approaches can be used, such as desirability function, heuristic or metaheuristic algorithms. In general, the desirability function embedded within statistics packages is used to detect the most suitable input parameters. However, some alternative techniques can be implemented to identify the optimal process parameters and to validate the results gathered by means of the conventional desirability function. In the last few decades, new metaheuristic algorithms gradually replaced the traditional optimization techniques in solving complex optimization problems [42]. The last column in Table 1 allows identifying contributions in which FSW parameters have been optimized. It is worth noting that, regardless of [39], most of them use a single optimization technique, thus ignoring the need of validating the selected approach with other optimization methods. To this end, we use three metaheuristic procedures, namely particle swarm optimization (PSO), differential evolution (DE) and harmony search (HS), to achieve the optimal process parameters able to maximize two performance measures. Differently from the genetic algorithm (GA), PSO, DE and HS were developed to work by means of a real encoding scheme of the problem under investigation and, as a result, they are more suitable than GA to solve optimization issues with continuous design variables. PSO [43] already affirmed its effectiveness for the selection of optimal parameters of welding processes and FSW as well [15,23] (see last column in Table 1). DE [44] recently emerged as the most suitable metaheuristic for the selection of input parameter of a friction stir welding process for AA2195-T8 aluminum alloy by exploiting a well-established thermal model [39]. HS is a relatively new nature-inspired evolutionary algorithm, which is inspired by the musical performance process that occurs when a musician searches for a better state of harmony [45].

In this paper, a prediction model based on RSM was developed for the friction stir welding process of the AA6082-T6 aluminum alloy. Three distinct process parameters, namely rotational speed, welding speed and tool plunging, have been varied according to a full factorial design of experiments to investigate the relationships with the tensile strength and the ductility of the welded joints. A set of supplementary experimental data have been used to validate the developed empirical formula and, in addition, different optimization techniques have been implemented for validation and comparison purposes. In particular, the conventional desirability function (DF) and the three mentioned metaheuristic (ME) algorithms have been implemented with the aim of comparing the predicted results with the experimental ones. The obtained outputs confirm the accuracy of the proposed metamodels as well as the effectiveness of the mentioned optimization techniques. The reminder of the paper is as follows. Section 2 deals with the experimental design of the problem under investigation. In Section 3 numerical results from both numerical and experimental analyses are investigated. Section 4 deals with the optimization procedure to identify the best process parameter for maximizing the two responses at hand, namely UTS and UE. Section 5 concludes the paper.

\section{Experimental Design}

\subsection{Overview of the Experimental Campaign}

The material investigated in the present work was AA6082-T6 aluminum alloy, supplied in the form of $2 \mathrm{~mm}$ thick sheets. The chemical composition of the alloy is shown in Table 2. 
Table 2. Chemical composition of AA6082-T6 aluminum alloy (\% weight).

\begin{tabular}{cccccccccccc}
\hline Material & Zn & Cu & Mn & Si & Fe & Mg & Cr & Ti & Ni & Al \\
\hline AA6082-T6 & 0.03 & 0.04 & 0.76 & 0.99 & 0.24 & 0.92 & 0.13 & 0.02 & 0.002 & bal. \\
\hline
\end{tabular}

Butt joints in AA6082-T6 blanks, characterized by a length of $180 \mathrm{~mm}$ and a width of $80 \mathrm{~mm}$, were obtained by means of a friction stir welding process (Figure 1a). Details about the equipment used for FSW operations are available in [46]. The high carbon steel tool, in pin configuration, was employed during the experimental campaign (Figure 1b); it was characterized by a shoulder diameter of $12 \mathrm{~mm}$, a truncated cone pin with a base diameter of $3.5 \mathrm{~mm}$, a height equal to $1.7 \mathrm{~mm}$ and a pin angle of $30^{\circ}$. The welding direction was chosen perpendicular to the rolling one and the starting configuration was assured by fixing blanks by means of a set of mechanical clamps. The friction stir welding processes were carried out by imposing constant values of rotational speed, welding speeds and tool plunging, varying in the ranges $1200-2500 \mathrm{rpm}, 30-100 \mathrm{~mm} / \mathrm{min}$ and $0.05-0.15 \mathrm{~mm}$, respectively. According to the scientific literature [47-50], all the welding operations were performed using a tilt angle of $2^{\circ}$. Rajendran et al. [47] investigated the effect of tilt angle on the mechanical properties of friction stir welded joints in aluminum alloys. It was recommended to use tool tilt angle less than $3^{\circ}$ to avoid weld joint defects. Specifically, the optimum mechanical behavior was obtained testing FSWed joints using a tool tilt angle equal to $2^{\circ}$. Chen et al. [48] observed that the low tilt angle reduces the flow of materials during the process that results in formation of kissing bond like structure in the stir zone while a high tilt angle results in flashes. Additionally, Barlas and Ozsarac [49] experimentally observed that the $2^{\circ}$ tilt can produce a defect free weld. Each joint was realized by performing a single FSW pass.

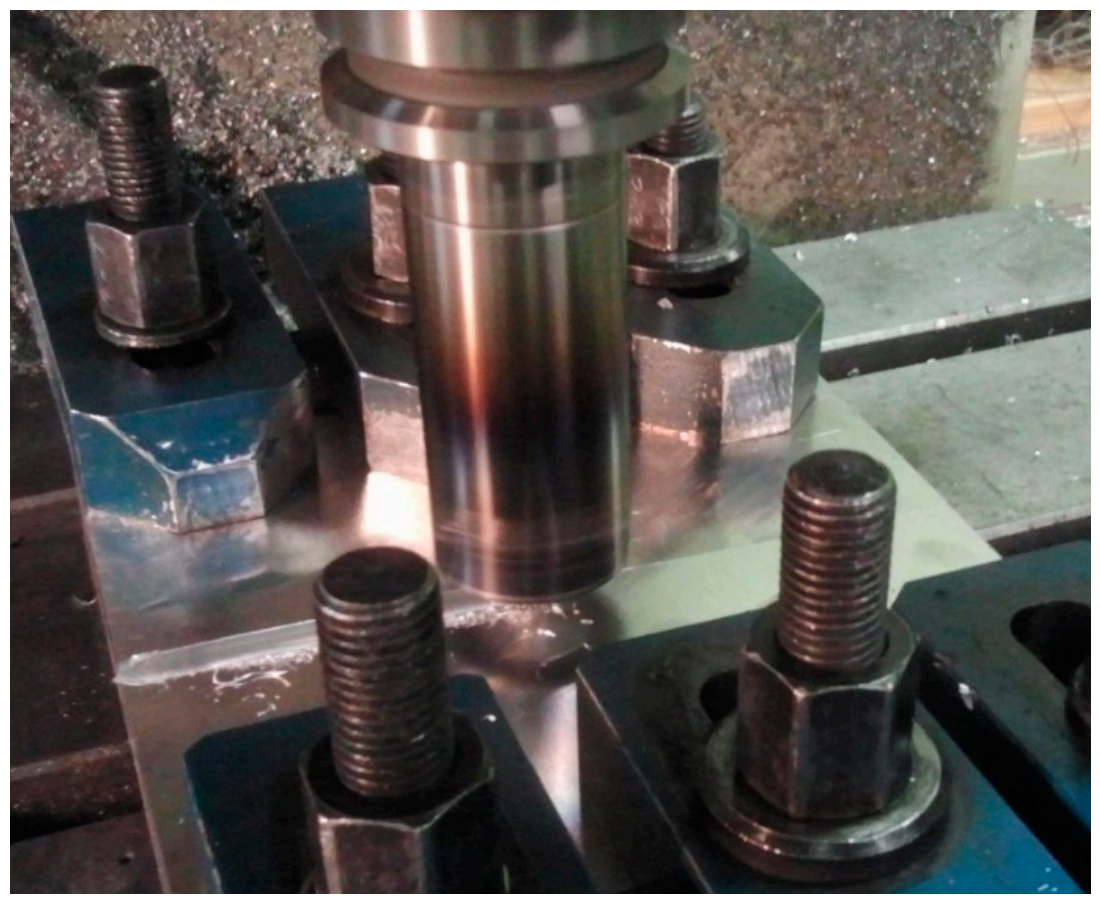

(a)

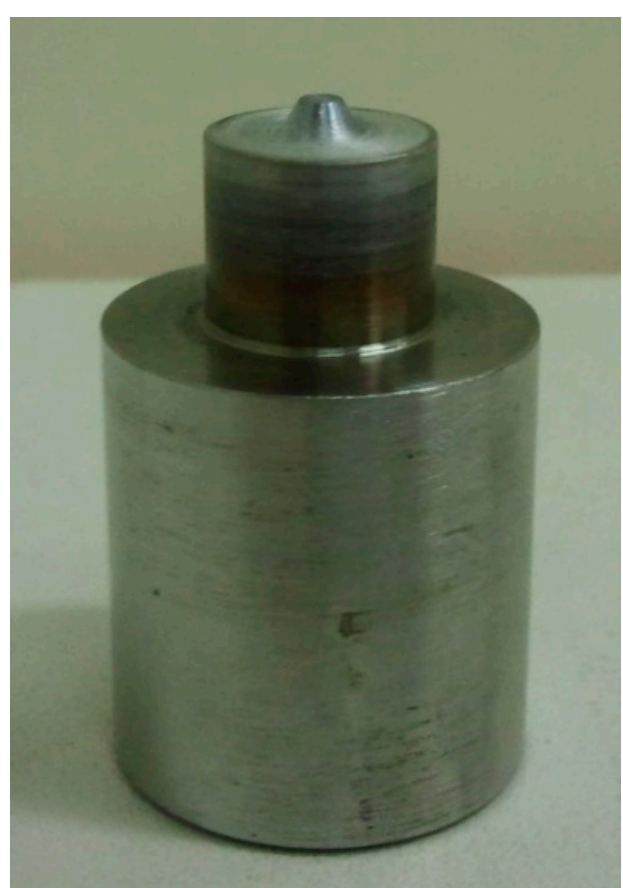

(b)

Figure 1. (a) Friction stir welding process of AA6082-T6 and (b) pin tool used for FSW.

The microstructure of the friction stir welded blanks was investigated using a ReichertJung $^{\mathrm{TM}}$ MeF-3s light optical microscope (Leica Microsystems, Berlin, Germany). The surfaces of samples were polished and then subjected to an etching with a solution containing $10 \mathrm{~mL}$ acetic acid, $6 \mathrm{~g}$ picric acid, $10 \mathrm{~mL}$ distilled water and $100 \mathrm{ml}$ of ethanol. The transverse cross section of each welded joint was analyzed, and details of the different 
zones were observed. The microstructure of the base material (BM) is shown in Figure 2 and the mean grain size values were evaluated by line intercept method according to the ASTM E112. Specifically, the BM mean grain size was equal to $20 \pm 2 \mu \mathrm{m}$.

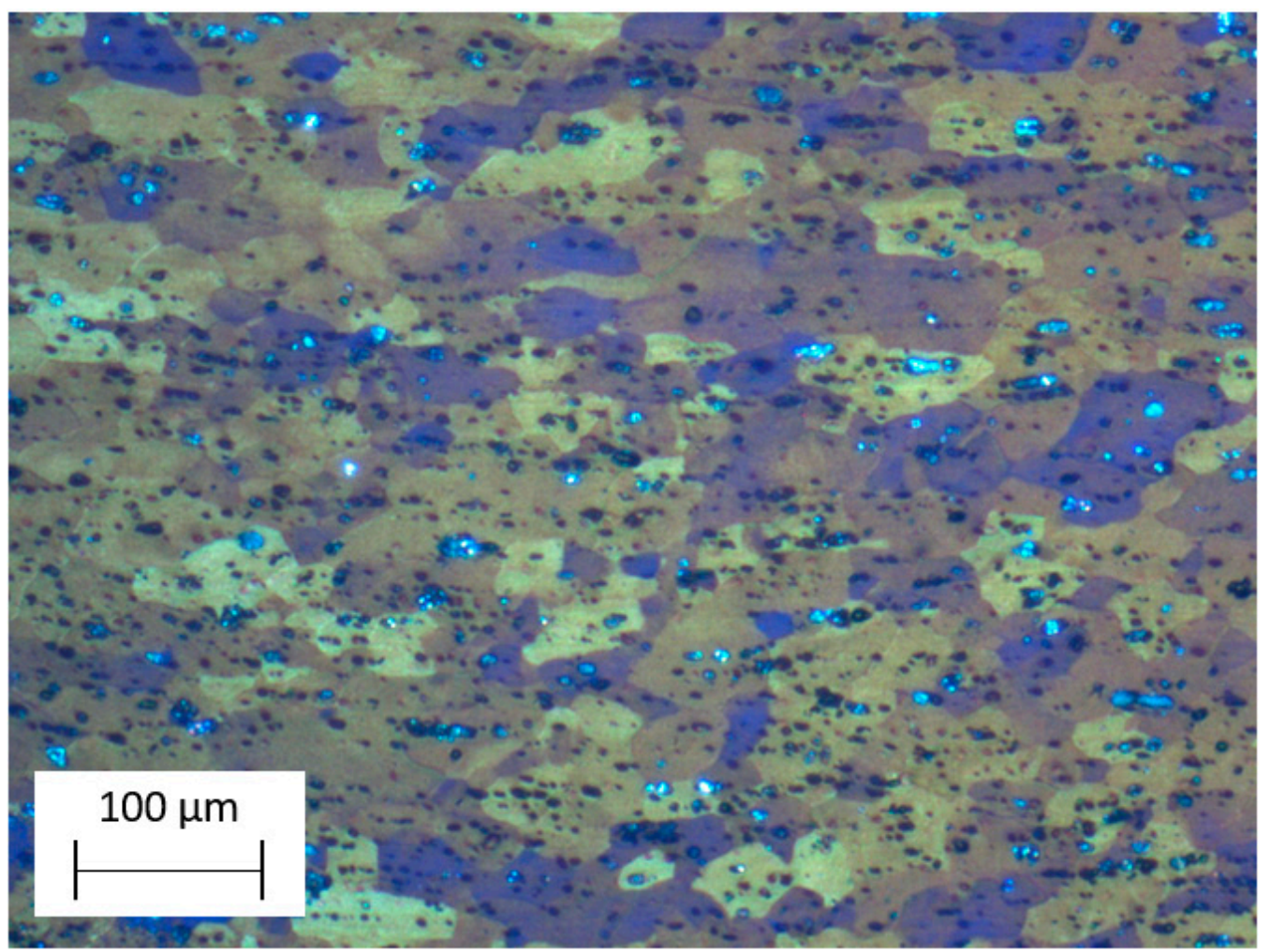

Figure 2. Microstructure of the AA6082-T6 aluminum alloy.

\subsection{Experimental Design Matrix}

Supported by the proposed literature review, tool plunging (TP), rotational speed $(\omega)$ and welding speed (v) were assumed as independent variables of the proposed experimental campaign. To the best of our knowledge, the effect of the tool plunging never has been investigated by the literature on FSW so far. Two response variables, namely UTS and UE were evaluated by means of tensile tests performed at room temperature using the servo-hydraulic universal testing machine (MTS Systems Corporation, Eden Prairie, MN, USA). Due to the smaller number of required tests, partial factorial design or completely randomized design (CRD) of experiments is typically employed by the literature for investigating the performance of FSW at varying process parameters. In order to gather the maximum quantity of information from the experimental investigations, in this study a full factorial design of experiments involving three factors at three levels was adopted, as shown in Table 3.

Table 3. Process parameters used for the experimental design (coded and actual values).

\begin{tabular}{ccccccccc}
\hline \multirow{2}{*}{ ID } & \multirow{2}{*}{ Parameter } & Notation & Variable & Unit & & \multicolumn{3}{c}{ Levels } \\
\cline { 6 - 9 } & & & & & Low (-1) & Mid (0) & High (+1) \\
\hline 1 & Tool plunging & $\mathrm{TP}$ & $\mathrm{x}_{1}$ & $\mathrm{~mm}$ & 0.05 & 0.1 & 0.15 \\
2 & Rotational speed & $\omega$ & $\mathrm{x}_{2}$ & $\mathrm{rpm}$ & 1200 & 1500 & 2500 \\
3 & Welding speed & $\mathrm{v}$ & $\mathrm{x}_{3}$ & $\mathrm{~mm} / \mathrm{min}$ & 30 & 60 & 100 \\
\hline
\end{tabular}

It is worth pointing out that levels assigned to each factor were selected with the aim of avoiding any visible external defect on the final welded joint. Table 4 reports the design matrix holding the entire set of $3^{3}=27$ coded and uncoded conditions concerning 
the proposed full factorial design of experiments [51]. Experiments were performed in randomized order to minimize the noise arising from uncontrollable variables, such as machine heating, surrounding humidity and temperature. Once the FSW operations were completed, each friction stir welded blanks was cut in order to obtain tensile samples. Tensile samples were prepared according to BS EN ISO 4136:2012 standard dimensions, with the loading direction perpendicular to the welding line, as described in Figure 3. The tensile tests were carried out at a constant crosshead speed of $0.1 \mathrm{~mm} / \mathrm{s}$. The results obtained by tensile tests carried out at the room temperature allowed the measurement of both UTS and UE as a function of the different welding parameters. Three replicates were performed for each parameter configuration and the mean values were computed.

Table 4. Design matrix with measured values of responses.

\begin{tabular}{|c|c|c|c|c|c|c|c|c|}
\hline \multicolumn{7}{|c|}{ Input Parameters (Coded/Uncoded) } & \multicolumn{2}{|c|}{ Responses } \\
\hline Run/Unit & $\begin{array}{c}\mathrm{x}_{1}(\mathrm{TP}) \\
(\mathrm{mm})\end{array}$ & $\begin{array}{c}x_{2}(\omega) \\
(\mathrm{rpm})\end{array}$ & $\begin{array}{c}x_{3}(v) \\
(\mathrm{mm} / \mathrm{min})\end{array}$ & $\begin{array}{c}\mathrm{x}_{1}(\mathrm{TP}) \\
(\mathrm{mm})\end{array}$ & $\begin{array}{c}x_{2}(\omega) \\
(\mathrm{rpm})\end{array}$ & $\begin{array}{c}x_{3}(v) \\
(\mathrm{mm} / \mathrm{min})\end{array}$ & $\begin{array}{c}\text { UTS } \\
\text { (MPa) }\end{array}$ & $\begin{array}{l}\text { UE } \\
(\%)\end{array}$ \\
\hline 1 & 1 & 0 & -1 & 0.15 & 1500 & 30 & 188.7 & 9.4 \\
\hline 2 & 0 & 1 & 0 & 0.1 & 2500 & 60 & 217.8 & 11.0 \\
\hline 3 & -1 & -1 & 1 & 0.05 & 1200 & 100 & 163.4 & 2.3 \\
\hline 4 & 1 & 1 & -1 & 0.15 & 2500 & 30 & 194.8 & 8.6 \\
\hline 5 & 0 & 1 & -1 & 0.1 & 2500 & 30 & 193.5 & 8.8 \\
\hline 6 & 1 & -1 & 1 & 0.15 & 1200 & 100 & 211.6 & 10.4 \\
\hline 7 & -1 & 1 & -1 & 0.05 & 2500 & 30 & 172.6 & 5.4 \\
\hline 8 & 1 & 1 & 0 & 0.15 & 2500 & 60 & 210.3 & 10.3 \\
\hline 9 & -1 & 0 & -1 & 0.05 & 1500 & 30 & 162.8 & 5.8 \\
\hline 10 & 0 & -1 & 1 & 0.1 & 1200 & 100 & 212.7 & 11.0 \\
\hline 11 & -1 & 1 & 1 & 0.05 & 2500 & 100 & 188.3 & 3.8 \\
\hline 12 & 0 & -1 & -1 & 0.1 & 1200 & 30 & 188.3 & 8.6 \\
\hline 13 & 1 & 0 & 0 & 0.15 & 1500 & 60 & 212.0 & 10.8 \\
\hline 14 & -1 & -1 & -1 & 0.05 & 1200 & 30 & 155.6 & 3.5 \\
\hline 15 & 0 & 0 & 0 & 0.1 & 1500 & 60 & 206.6 & 10.6 \\
\hline 16 & -1 & -1 & 0 & 0.05 & 1200 & 60 & 175.2 & 3.8 \\
\hline 17 & -1 & 1 & 0 & 0.05 & 2500 & 60 & 194.1 & 6.2 \\
\hline 18 & 0 & 0 & -1 & 0.1 & 1500 & 30 & 191.0 & 9.2 \\
\hline 19 & -1 & 0 & 0 & 0.05 & 1500 & 60 & 183.2 & 6.1 \\
\hline 20 & 0 & 0 & 1 & 0.1 & 1500 & 100 & 212.3 & 8.3 \\
\hline 21 & 1 & 1 & 1 & 0.15 & 2500 & 100 & 212.7 & 6.1 \\
\hline 22 & 0 & 1 & 1 & 0.1 & 2500 & 100 & 215.6 & 5.5 \\
\hline 23 & -1 & 0 & 1 & 0.05 & 1500 & 100 & 189.6 & 5.5 \\
\hline 24 & 1 & -1 & 0 & 0.15 & 1200 & 60 & 200.3 & 9.6 \\
\hline 25 & 1 & 0 & 1 & 0.15 & 1500 & 100 & 209.6 & 8.3 \\
\hline 26 & 1 & -1 & -1 & 0.15 & 1200 & 30 & 177.2 & 8.4 \\
\hline 27 & 0 & -1 & 0 & 0.1 & 1200 & 60 & 197.2 & 10.7 \\
\hline
\end{tabular}

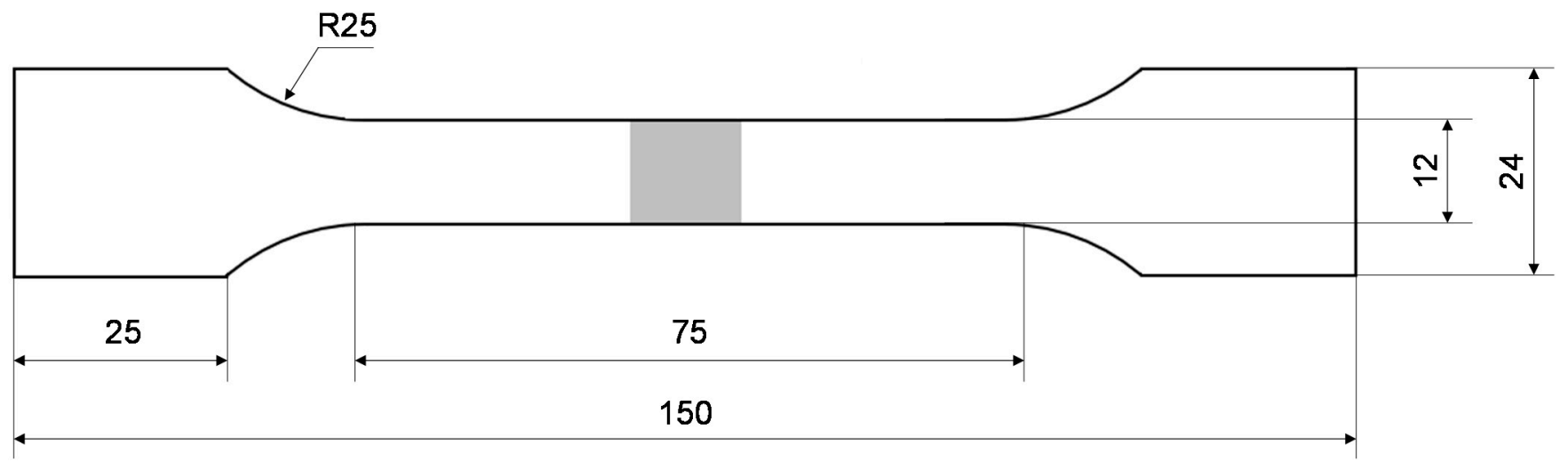

Figure 3. Geometry and dimensions of the tensile specimens (unit of measurement: $\mathrm{mm}$ ). 
Table 5 summarizes the mechanical properties of the base alloy, which can be used as reference in evaluating the joint quality. Such results match those reported by Lukács et al. [52] and Moreira et al. [53].

Table 5. Mechanical properties of the AA6082-T6 base alloy.

\begin{tabular}{ccccc}
\hline Material & $\begin{array}{c}\text { Elastic Modulus } \\
(\text { GPa) }\end{array}$ & $\begin{array}{c}\text { Yield Strength } \\
(\mathbf{M P a})\end{array}$ & $\begin{array}{c}\text { Ultimate Tensile Strength } \\
\text { (MPa) }\end{array}$ & $\begin{array}{c}\text { Ultimate Elongation } \\
(\mathbf{\%})\end{array}$ \\
\hline AA6082-T6 & 68.2 & 271.8 & 318.4 & 17.4 \\
\hline
\end{tabular}

\subsection{Building the Process Metamodels for UTS and UE}

A mathematical metamodel based on non-linear regression allows establishing a relationship between input and output variables. Particularly, the consistency of such a regression model is validated through a proper analysis of variance (ANOVA).

As mentioned earlier, the response surface methodology on the full factorial DOE was employed to develop an empirical model in the form of multiple regression equation wherein a set of independent variables (factors) affect a dependent (response) variable to be optimized [54]. In most experimental issues the independent factors $x$ can be correlated to a response $y$ through a functional relationship, as follows:

$$
y=\Phi(x) \pm \varepsilon
$$

The function $\Phi$ connecting response variable and influencing factors is denoted as the response surface or response function. The residual $\varepsilon$ represents the fitting error. In general, the mathematical form of $\Phi$ can be properly approximated by a second order polynomial (regression) equation as in Equation (2).

$$
y=b_{0}+b_{1} x_{1}+b_{2} x_{2}+b_{3} x_{3}+b_{11} x_{1}^{2}+b_{22} x_{2}^{2}+b_{33} x_{3}^{2}+b_{12} x_{1} x_{2}+b_{13} x_{1} x_{3}+b_{23} x_{2} x_{3}+\varepsilon
$$

where $b_{0}$ is the term related to the arithmetic average of the response values for the whole set of runs, $b_{i}(i=1, \ldots, 3)$ are the coefficient related to the main parameters, $b_{i i}(i=1, \ldots, 3)$ are the quadratic terms coefficients, and $b_{i j}(i, j=1, \ldots, 3 \mid i \neq j)$ are the interaction coefficients. Finding the regression coefficients $b$ would be a demanding task; thus, MINITAB ${ }^{\circledR} 17$ (Minitab 17 Statistical Software, Minitab LLC - State College, PA, USA) commercial package has been adopted to select the coefficients of the second order regression models by using experimental data. The obtained second order empirical formulas in uncoded values for UTS and UE are shown in Equations (3) and (4), respectively:

$$
\begin{gathered}
\text { UTS }=-7.2+1591 x_{1}+0.0753 x_{2}+ \\
+1.377 x_{3}-6400 x_{1} x_{1}-0.000015 x_{2} x_{2}-0.00796 x_{3} x_{3}-0.0716 x_{1} x_{2} \\
+1.133 x_{1} x_{3}-0.000079 x_{2} x_{3} \\
\begin{aligned}
U E=-22.8+268.8 x_{1}+0.01217 x_{2}+ & 0.2192 x_{3}-980 x_{1} x_{1}-0.000002 x_{2} x_{2}-0.001294 x_{3} x_{3}-0.01991 x_{1} x_{2} \\
+ & 0.061 x_{1} x_{3}-0.000038 x_{2} x_{3}
\end{aligned}
\end{gathered}
$$

\subsection{ANOVA Analyses to Check Models Adequacy}

Two ANOVA analyses were developed to investigate how the provided process parameters affect the two output variables and to validate the corresponding metamodels as well. Table 6 shows the results related to the ANOVA analysis on UTS. $p$-values and remarks highlight as linear and square terms are statistically significant influencing factors for UTS. On the other hand, all the 2-way interactions did not significantly affect the response variable. To assess how close the experimental data were to the fitted regression model, S-values, R-squared (R-sq) and the adjusted R-sq ( $R^{2}$-adj) have to be observed. Model summary on Table 6 confirm the high accuracy of the developed metamodel in predicting the experimental data. 
Table 6. ANOVA analysis for ultimate tensile strength (UTS).

\begin{tabular}{ccccccc}
\hline Source & DF & Adj SS & Adj MS & F-Value & $p$-Value & Remarks \\
\hline Model & 9 & 7986.49 & 887.39 & 24.32 & 0.000 & Significant \\
Linear & 3 & 5362.06 & 1787.35 & 48.99 & 0.000 & Significant \\
Square & 3 & 2183.73 & 727.91 & 19.95 & 0.000 & Significant \\
2-Way Interaction & 3 & 161.42 & 53.81 & 1.47 & 0.257 & Insignificant \\
Error & 17 & 620.25 & 36.49 & - & - & - \\
Total & 26 & 8606.74 & - & - & - & - \\
Model Summary: S $=1.16613 ; \mathrm{R}-\mathrm{sq}=87.32 \%$; R-sq(adj) $=80.61 \%$; R-sq(pred $)=67.69 \%$ \\
\hline
\end{tabular}

Table 7 depicts the findings from the ANOVA concerning with the UE response. In this case linear, squared and 2-way interaction coefficients were statistically significant. Values of determination coefficient (R-sq) and adjusted determination coefficient $\left(\mathrm{R}^{2}\right.$-adj) reported in the model summary denote as the actual data predicted by the proposed regression model were quite well fitted, even though their values were slightly lower than those earlier observed.

Table 7. ANOVA analysis for ultimate elongation (UE).

\begin{tabular}{ccccccc}
\hline Source & DF & Adj SS & Adj MS & F-Value & $p$-Value & Remarks \\
\hline Model & 9 & 159.229 & 17.6921 & 13.01 & 0.000 & Significant \\
Linear & 3 & 79.939 & 26.6463 & 19.60 & 0.000 & Significant \\
Square & 3 & 52.740 & 17.5801 & 12.93 & 0.000 & Significant \\
2-Way Interaction & 3 & 15.265 & 5.0883 & 3.74 & 0.031 & Significant \\
Error & 17 & 23.117 & 1.3599 & - & - & - \\
Total & 26 & 182.347 & - & - & - & - \\
Model Summary: S $=1.16613 ; \mathrm{R}-\mathrm{sq}=87.32 \%$; R-sq(adj) $=80.61 \%$; R-sq(pred $)=67.69 \%$ \\
\hline
\end{tabular}

To sum up, the accuracy of the proposed second order regression models in predicting both responses can be demonstrated by the following two findings from the ANOVA analyses: (i) $p$-values of both models for the sources of regression, i.e., UTS and UE, were lower than 0.05 and (ii) models Fisher ratio values were significantly higher than the critical F-ratios at the $99 \%$ confidence level. The normal probability plots of residuals for UTS and UE are depicted in Figure 4. Both of them revealed most residuals fall on the straight line, thus confirming the errors were normally distributed. A graphical comparison between predicted and experimental values of the response variables are depicted in Figure 5, which also reaffirmed the slightly better fitting accuracy of the UTS model with respect to the UE related one.

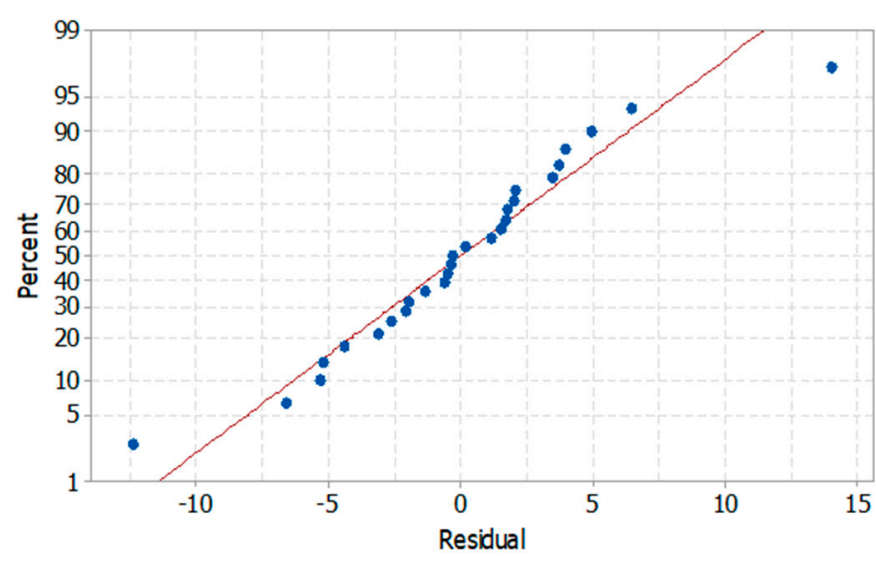

(a)



(b)

Figure 4. Normal probability plots of residuals: (a) UTS and (b) UE. 


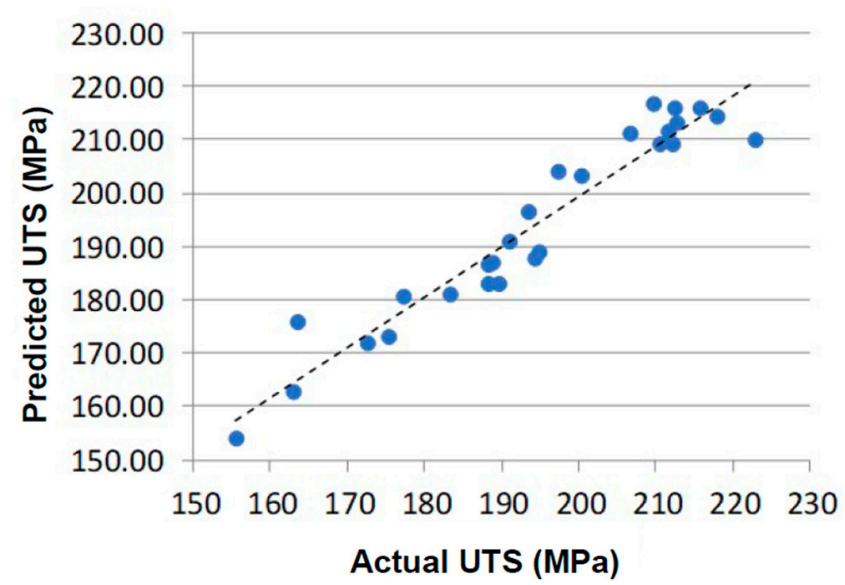

(a)

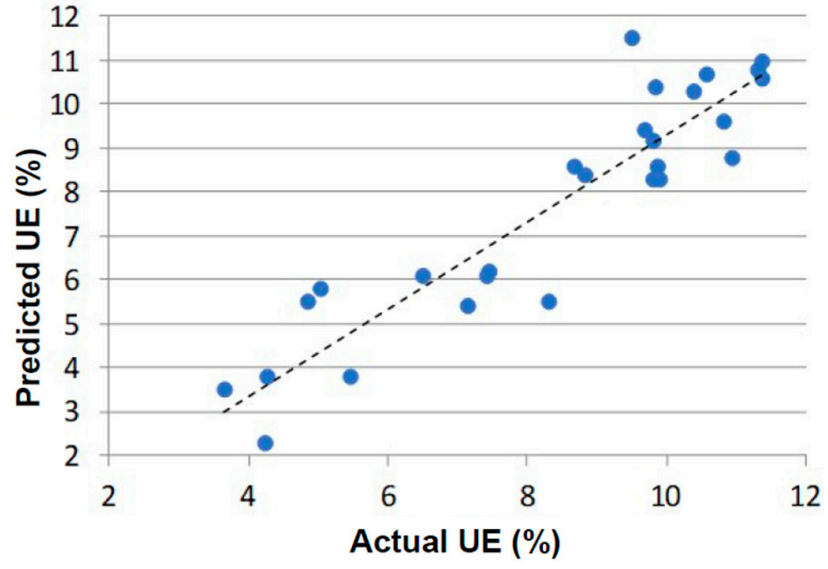

(b)

Figure 5. Predicted vs. actual responses plot of: (a) UTS and (b) UE.

\subsection{Validation of the Metamodels}

To further verify the accuracy of the proposed metamodels, five additional experimental tests, whose process parameters were randomly selected in the ranges reported in Table 4, were employed to assess the relative discrepancy between the actual results and those predicted by the proposed empirical formula. Specifically, Table 8 shows the chosen parameters and the obtained results (UTS * and UE ${ }^{*}$ ) as well. The relative errors in percentage for each test over UTS and UE, denoted with $\Delta_{-}$UTS and $\Delta \_U E$, respectively, are shown in Table 8 . The maximum deviation in terms of UTS was equal to $2.47 \%$ while the higher one under the UE viewpoint was equal to $11.34 \%$, thus confirming the higher accuracy of the UTS-related metamodel. However, as for both UTS and UE, the minimum values of relative percent error and the mean absolute errors fulfilled the expected requirements in terms of modeling accuracy.

Table 8. Validation of the proposed metamodels.

\begin{tabular}{|c|c|c|c|c|c|c|c|c|c|}
\hline \multirow[b]{2}{*}{ No. } & \multicolumn{3}{|c|}{ Process Parameters } & \multicolumn{2}{|c|}{ Actual Values } & \multicolumn{2}{|c|}{ Predicted Values } & \multicolumn{2}{|c|}{ Deviations } \\
\hline & $\begin{array}{c}\mathrm{TP} \\
(\mathrm{mm})\end{array}$ & $\underset{(\mathrm{rpm})}{\omega}$ & $\begin{array}{c}\mathrm{v} \\
(\mathrm{mm} / \mathrm{min})\end{array}$ & $\begin{array}{c}\text { UTS } \\
\text { (MPa) }\end{array}$ & $\begin{array}{l}\text { UE } \\
(\%)\end{array}$ & $\begin{array}{l}\text { UTS * } \\
\text { (MPa) }\end{array}$ & $\begin{array}{l}\mathrm{UE}^{*} \\
(\%)\end{array}$ & $\underset{(\%)}{\Delta \_U T S}$ & $\underset{\substack{\left.\Delta_{\mathbf{O}} \mathrm{U}\right) \\
\mathrm{UE}}}{\Delta}$ \\
\hline 1 & 0.05 & 1850 & 60 & 188.8 & 6.15 & 187.8 & 6.59 & -0.53 & 7.14 \\
\hline 2 & 0.12 & 1500 & 85 & 215.4 & 10.93 & 219.9 & 10.99 & 2.08 & 0.59 \\
\hline 3 & 0.07 & 1900 & 45 & 194.6 & 7.94 & 196.4 & 8.78 & 0.95 & 10.63 \\
\hline 4 & 0.1 & 1400 & 65 & 206.3 & 10.72 & 210.8 & 10.78 & 2.18 & 0.56 \\
\hline 5 & 0.12 & 2200 & 90 & 218.5 & 10.76 & 223.9 & 9.54 & 2.47 & -11.34 \\
\hline- & - & - & - & - & - & mear & arror & 1.64 & 6.04 \\
\hline
\end{tabular}

\section{Results and Discussion}

The scientific literature reports that FSW process results in intense plastic deformation and temperature distribution within and around the stirred zone of the workpiece. Very complex mechanisms occur during the weld formation, due to thermal and micro- and macro-mechanical effects influenced by the different process parameters [55-58]. For this reason, the FSW process parameters, such as the TP, $\omega$ and $v$ values, must be carefully selected in order to guarantee an efficient and successful welding operation $[46,50,59]$.

Regardless of the process parameters investigated in the present work, fracture occurs in the heat affected zone, as shown in Figure 6 in which a typical fractured tension tested FSWed sample can be observed. Such a result fits the findings achieved by that observed by Costa et al. on friction stir welded AA6082 blanks [60]. They attributed such behavior at the occurrence of failure in this zone for very small values of plastic strain due to the absence 
of pure uniaxial loading conditions in the heat affected zone of FSWed joints. Additionally, Mishra and Ma demonstrated that the different zones of FSWed joints are characterized by dissimilar resistances to deformation due to differences in grain size and precipitate size and distribution [55]. Among these zones, the heat affected one exhibited the lowest strength due to significantly coarsened precipitates and the development of the precipitatefree zones. As a matter of fact, it can be observed in Figure 6 that the low-strength heat affected zone locally elongated, resulting in necking and fracture, whereas the nugget zone experienced only a very small strain.

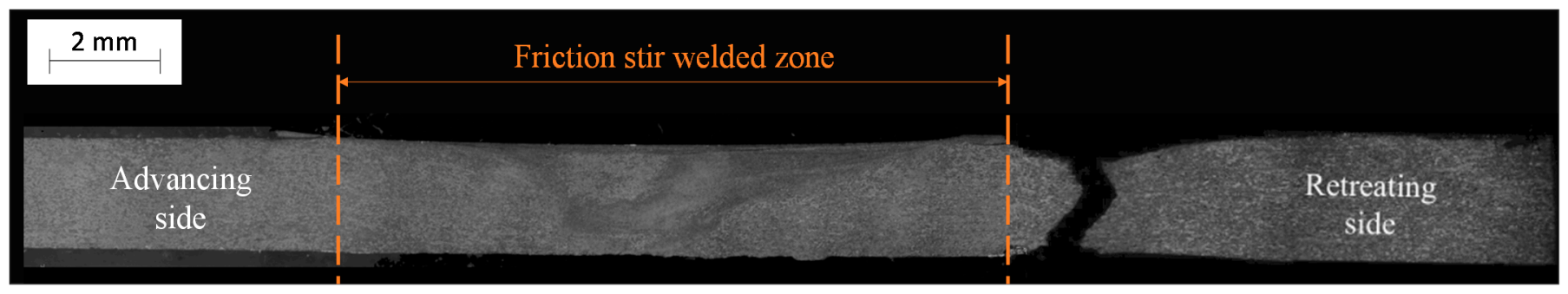

Figure 6. Typical macrostructure of a fractured tension tested FSWed sample ( $\omega=1500 \mathrm{rpm} ; \mathrm{v}=60 \mathrm{~mm} / \mathrm{min})$.

In order to infer about the influence of the process parameters on UTS and UE of friction stir welded AA6082-T6 joints, a series of contour plots and surface plots will be investigated in the following subsections. Notably, contour plots, due to their typical circular shape, allow one to detect a possible independence of factors with a given response. In addition, they are able to visually indicate the region of optimal parameters configuration. Since the developed response surfaces arise from a second order regression model, investigating a surface response could be a tricky task if compared with the simple series of parallel lines that characterize responses connected to first order models. As a result, contour plots play an important role in the study of RSM based analyses.

\subsection{Effect of FSW Parameters on UTS}

Figure 7a shows the effect of process parameters TP, $\omega$ and $v$ on the ultimate tensile strength. As far as the effect of TP on UTS is concerned, Figure 7a shows that UTS values increase with TP until a maximum value was reached. Then, the UTS decreased as much as TP approached the upper bound value adopted in the present paper (i.e., $0.15 \mathrm{~mm}$ ). A similar behavior can be observed for the rotational and the welding speeds (Figure 7a), even though the variability of UTS with $\omega$ was less significant than that exhibited with $v$.

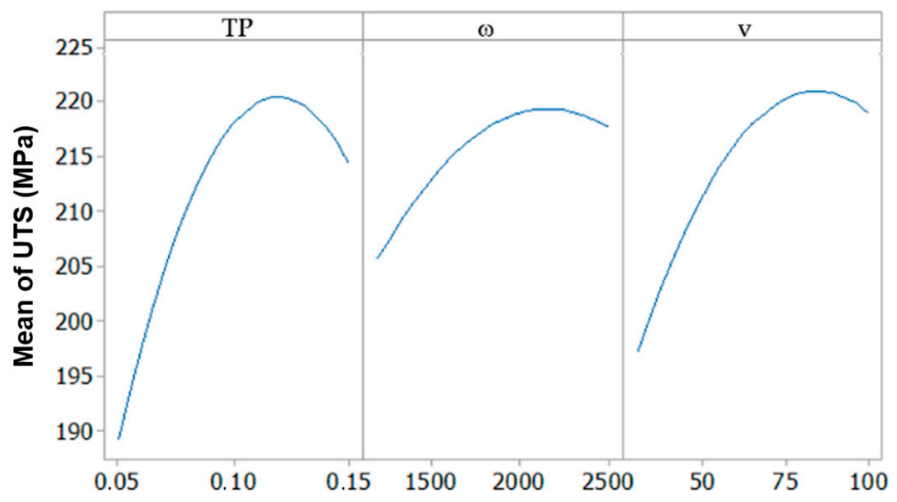

(a)

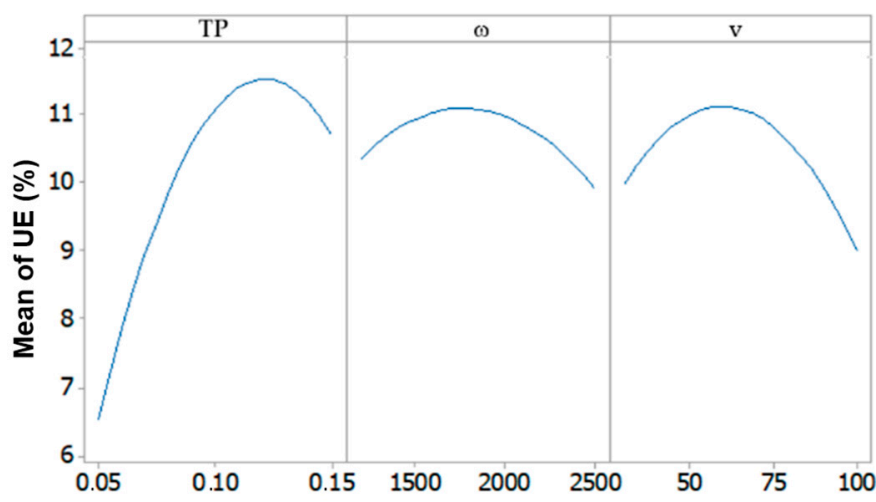

(b)

Figure 7. Effect of tool plunging, rotational speed and welding speed on: (a) UTS and (b) UE. 
The interaction effects of any two process parameters on UTS are shown by both contour plots and surface plots, as reported in Figure 8. The more circular is the shape of the contour plot, the higher is the independence between the factors under investigation.
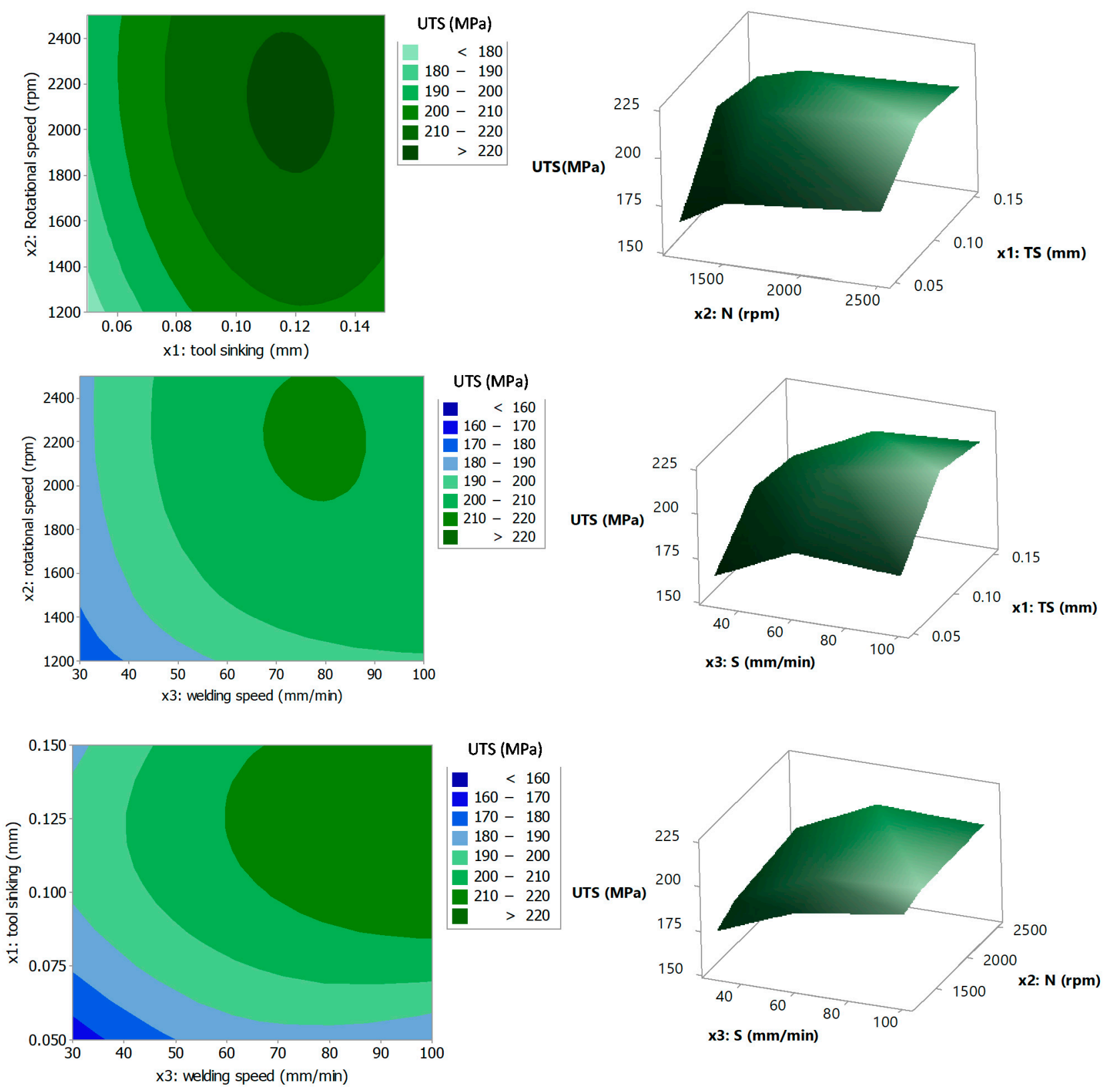

Figure 8. Contour plots and surface plots of UTS.

The combined influence of rotational speed and tool plunging led to higher UTS when $\omega$ and TP roughly varied in the range $1800-2400 \mathrm{rpm}$ and $0.1-0.13 \mathrm{~mm}$, respectively. A proper combination between $\omega$ and TP favored heat input, mixing and stirring actions during FSW. As shown by Cabibbo et al. in [61], irrespective of the FSW process parameters taken into account, the stirred zone is characterized by fine equiaxed grains (Figure 9), contrary to the base material, which exhibited large and elongated grains (Figure 2). Such a result demonstrates the occurrence of the dynamic recrystallization and the grain refinement within the SZ. However, as demonstrated by Shehabeldeen et al. on AA6061 friction stir welded joints [14], the lower the $\omega$ value, the poorer is the heat input produced. As a consequence, the workpiece cannot achieve a temperature able to enable an intense stirring action of the alloy (Figure 9a). On the contrary, whether $\omega$ is too high, an excessive temper- 
ature occurs and the consequent grain coarsening, also associated to a turbulent material flow, in the stir zone negatively affects the mechanical strength of the joint (Figure 9b). These findings agree with results shown by Elangovan et al. [25,35], Babu et al. [13], Verma et al. [62] and Forcellese and Simoncini [63].

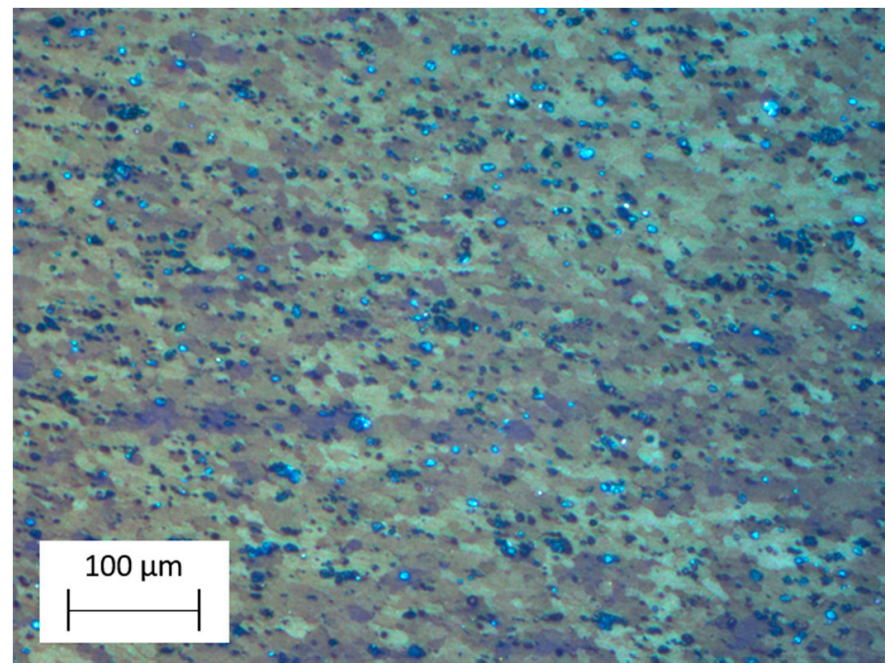

(a)

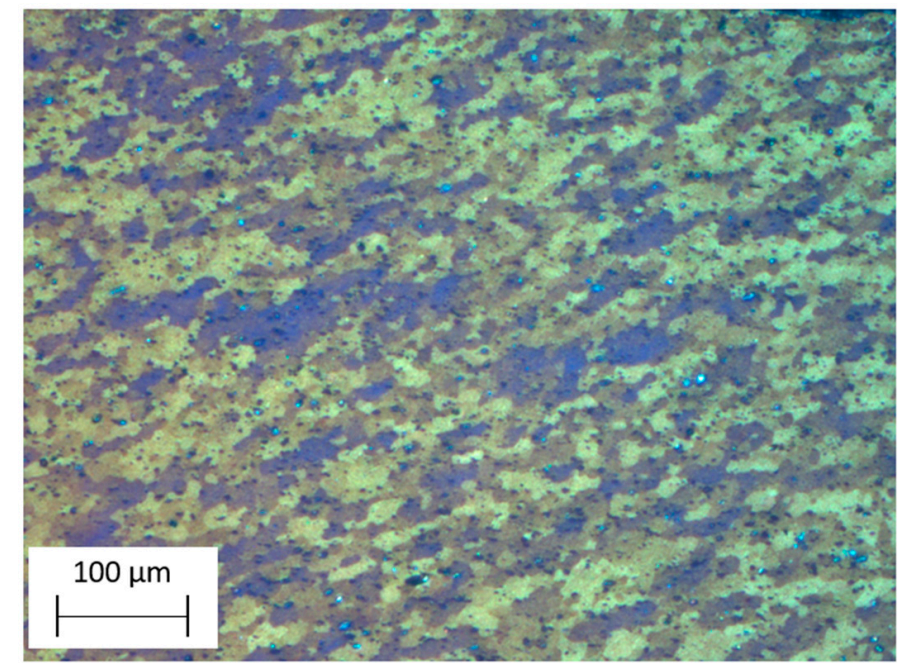

(b)

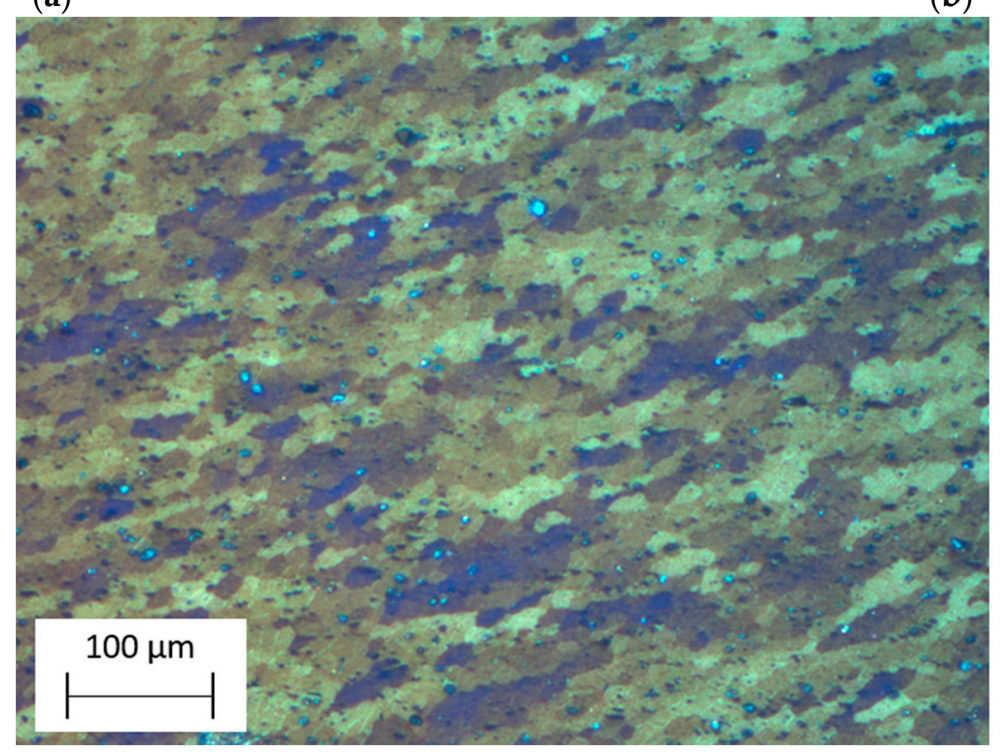

(c)

Figure 9. Typical microstructure of stirred zones of FSWed joints obtained at different rotational speeds: (a) $\omega=1200 \mathrm{rpm}$ and $\mathrm{v}=100 \mathrm{~mm} / \mathrm{min}$; (b) $\omega=2500 \mathrm{rpm}$ and $\mathrm{v}=100 \mathrm{~mm} / \mathrm{min} ;(\mathbf{c}) \omega=2500 \mathrm{rpm}$ and $\mathrm{v}=60 \mathrm{~mm} / \mathrm{min}(\mathrm{TP}=0.1 \mathrm{~mm})$.

Even the tool plunging plays a key role for enhancing the mechanical properties of joints. In fact, a proper value of plunging depth ensures a good contact between the shoulder and the workpiece top surface. As a matter of fact, as reported by Mishra and Ma in [55], when the TP value is too low, the tool shoulder does not contact the top surfaces of blanks. Thus, the rotating shoulder cannot move the stirred material efficiently from the front to the back of the pin, resulting in the generation of defective welds, with inner channels or surface grooves (Figure 10a). When the TP value was too deep, the shoulder plunged into the sheet blanks generating an excessive flash and, consequently, producing a concave weld characterized by a local thinning of the joint (Figure 10b). Both of these tool plunging-limit conditions yield poor mechanical properties of the FS welded joint. 


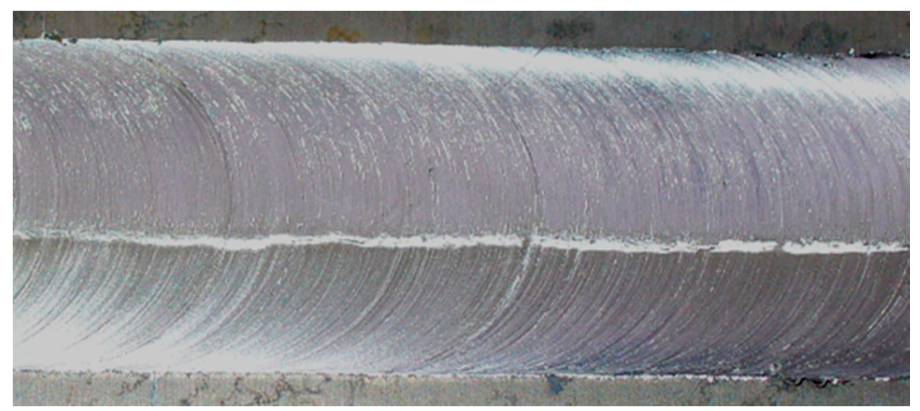

(a)

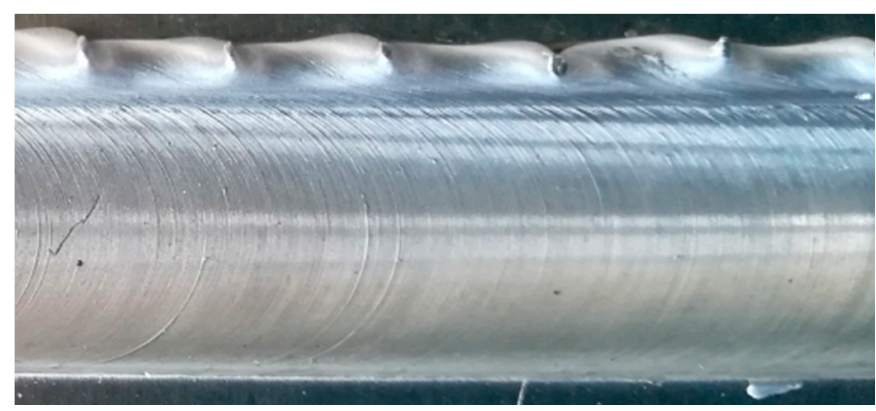

(b)

Figure 10. Defective FSWed samples obtained with: (a) small and (b) deep tool plunging.

As far as the interaction between TP and $\mathrm{v}$ is concerned, it can be observed that the UTS can be improved by increasing both parameters. However, by comparing the interactions of TP with both rotational and welding speed it was clear as joint UTS can be improved by adopting TP values roughly ranging from 0.10 to 0.13 .

Among the process parameters affecting the mechanical properties of the FSW joints, the welding speed plays a key role in terms of the extent and heating rate of the welded zone. As reported by Elangovan et al. in [25], higher v values are associated with lower heat inputs, which result in faster cooling rates of the welded joint. Such a phenomenon may strongly reduce the extension of the metallurgical transformations during welding (such as solubilization, reprecipitation and coarsening of precipitates) and the local strength of specific regions across the weld zone accordingly. Whether the welding speed is too high, defects may appear along the welded joint, thus increasing the risk of crack propagation during a tensile test. On the contrary, a higher heat generation occurs at lower welding speeds, which favor softening of the workpiece material and growth of the grain size (Figure 9c), thus reducing the UTS value. Looking at the interaction plots involving the welding speed on one hand and both $\omega$ and TP on the other hand, it was clear as higher UTS values were assured by v values in the range between 65 and $85 \mathrm{~mm} / \mathrm{min}$.

Similarly to Verma and Misra [1] and Mishra and Ma [55], findings from the proposed analysis show rotational and welding speeds had a stronger influence on the UTS of the welded joint, clearly due to their role in terms of frictional heat generation, cooling rate and heat dissipation, which affect the gradients of temperature within and around the welded area. A similar result was obtained by Bruni et al. on FSWed joints in the AZ31 magnesium alloy [10], in which a correlation between the joint mechanical performances and the rotational speed/welding speed ratio was investigated by means of experimental and numerical analyses. To sum up, in order to enhance the tensile strength of AA6082-T6 FSWed joints, TP, $\omega$ and $v$ should vary in the ranges $0.1-0.13 \mathrm{~mm}, 1900-2400 \mathrm{rpm}$ and $65-85 \mathrm{~mm} / \mathrm{min}$, respectively.

\subsection{Effect of FSW Parameters on UE}

The FSW process parameters also affected the ductility of joint. The main effect plots on Figure $7 \mathrm{~b}$ show the influence of TP, $\omega$ and $v$ on UE in percentage. It can be observed that UE increased with TP until a peak value was reached, and then decreased. A similar trend was obtained as a function of rotational speed and welding speed. However, the variability of UE with the rotational speed was less marked than that exhibited with tool plunging and welding speed. Following the same procedure adopted for UTS response, Figure 11 shows the interaction effects of any two process parameters on the ultimate elongation in percentage by means of contour plots and surface plots. 

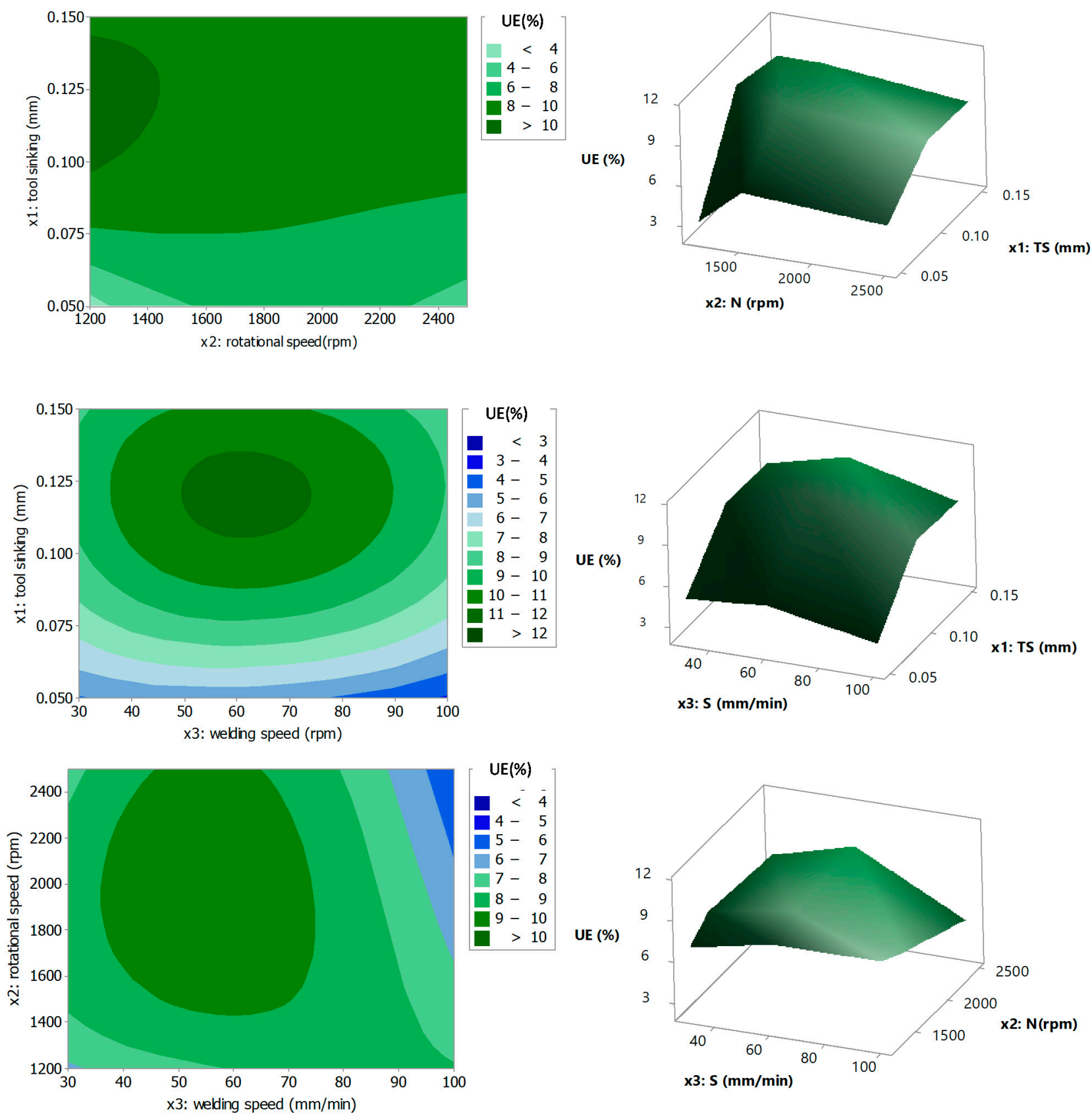

Figure 11. Contour plots and surface plots of UE.

As far as the effect between the tool plunging and both rotational and welding speeds are concerned, it can be noticed that the UE values worsened as TP was set to low values, due to the defects generated by the insufficient contact between the shoulder and the top surface of blanks (Figure 10a). Even a high tool plunging caused a reduction in UE due to the high reduction in the joint thickness, evident from the excessive burr formation (Figure 10b). Furthermore, steps were developed between the material not involved in the FSW process and the trace left by the shoulder on the top surface of the joint, causing a zone of stress concentration. Therefore, a suitable TP value should vary between about 0.11 and 0.13 in order to assure high ductility.

Conforming to the results obtained by Elatharasan and Kumar [27], it appeared midlow values of rotational speed, properly combined with TP and v values, enhanced the ultimate elongation response. As a result, it seems the rotational speed had a weaker impact on the ductility of the welded joint in comparison with what was experienced about UTS. 
The range in which the welding speed should vary for increasing the UE value was larger than that observed for UTS. As known, the welding speed was responsible for the frictional heating; thus, a high welding speed could yield poor plastic flow, also causing a scarce consolidation of the metal interface. On the other hand, due to a high frictional heating generation, low $\mathrm{v}$ values facilitated the material softening and the grain coarsening as well, thus enhancing the mechanical properties of the joint [55]. Furthermore, too low welding speeds make insufficient the corresponding friction heating, thus reducing the mechanical response also in terms of UE.

\section{Optimization of FSW Parameters}

One of the main objectives of the present research work was to identify the process parameters able to maximize UTS and UE for friction stir welded joints in the AA6082-T6 aluminum alloy. Mathematically, the corresponding unconstrained optimization problem can be formulated as follows:

$$
\max y=f\left(x_{1}, x_{2}, x_{3}\right)
$$

s.t.

$$
\begin{gathered}
0.05 \leq \mathrm{x}_{1} \leq 0.15 \\
1200 \leq \mathrm{x}_{2} \leq 2500 \\
30 \leq \mathrm{x}_{3} \leq 100
\end{gathered}
$$

where $\mathrm{y}$ is UTS (or UE) while $\mathrm{x}_{1}, \mathrm{x}_{2}$ and $\mathrm{x}_{3}$ are the independent variables (i.e., the process parameters corresponding to $\mathrm{D}, \boldsymbol{\omega}$ and $\mathrm{v}$ ) of the second order metamodels mentioned in the previous sections. Metaheuristic algorithms mentioned in Section 1, i.e., particle swarm optimization (PSO), differential evolution (DE) and harmony search (HS), were used to achieve the optimal process parameters able to maximize the responses at hand. The desirability function method, which is inbuilt in Minitab 17 software, was also used to identify the best process parameters. For the sake of a fair comparison, the same population size NP and termination criterion based on the maximum number of generations (Max_G) were set for each metaheuristic. The rest of control parameters adopted for each metaheuristic were set at the values recommended by the original authors (Table 9).

Table 9. Control parameter of metaheuristics (MEs).

\begin{tabular}{cccccc}
\hline & PSO & \multicolumn{2}{c}{ HS } & DE \\
\hline$N P$ & 30 & $N P$ & 30 & $M a x_{-} G$ & 30 \\
Max_G & 500 & $M a x_{-} G$ & 500 & $C R$ & 0.8 \\
$C 1$ & 2 & $H M C R$ & 0.9 & $F$ & 0.2 \\
$C 2$ & 2 & $P A R$ & 0.2 & - & - \\
$w_{\max }$ & 0.9 & $B W$ & 0.001 & - & - \\
$w_{\text {min }}$ & 0.4 & - & - & - \\
\hline
\end{tabular}

Since all metaheuristics work on the basis of a stochastic mechanism, 100 runs were executed at different random seeds so as to produce sufficient statistical data. All algorithms were coded in Matlab R2019 (MathWorks 1 Apple Hill Drive Natick, MA 01760-2098_USA) and all experiments were carried out using a MacBook Pro equipped with a $2.6 \mathrm{GHz}$ Intel Core 7 and 8 GB DDR3 RAM at $1600 \mathrm{MHz}$. The computational time each metaheuristic needed to achieve the best solution was lower than 0.1 seconds for all runs. The average results and the standard deviations in terms of UTS and UE from the computational experiments are reported in Table 10. All the proposed MEs reached, on average, the same optimal UTS and UE values. The standard deviations confirmed as the control parameters were adequately selected, even though HS presents relatively lower values than the other competitors. 
Table 10. Computational results obtained by MEs.

\begin{tabular}{ccccc}
\hline Metaheuristic & UTS_ave (MPa) & UTS_stdev & $\begin{array}{c}\text { UE_ave } \\
\mathbf{( \% )}\end{array}$ & UE_stdev \\
\hline PSO & 222.64 & $3.43 \times 10^{-13}$ & 12.26 & $3.57 \times 10^{-15}$ \\
DE & 222.64 & $3.43 \times 10^{-13}$ & 12.26 & $3.57 \times 10^{-15}$ \\
HS & 222.64 & $2.73 \times 10^{-5}$ & 12.26 & $9.46 \times 10^{-6}$ \\
\hline
\end{tabular}

Figure 12 shows a comparison between the results from the ME algorithms and those from the desirability function by Minitab 17. Looking at the optimal process parameters it is worthy to point out as both methods selected the same TP value of $0.12 \mathrm{~mm}$, regardless of the specific objective function. The other parameters roughly assumed the same value when UTS had to be maximized, while a significant difference existed for the ultimate elongation response. As far as UTS is concerned, a small relative error characterized the difference between predicted and actual UTS values. The process parameters obtained by the ME algorithms over the regression model in Equation (1) allow one to achieve the higher actual UTS (221.6 MPa) with a very small fitting error $(0.47 \%)$. Although DF provided a higher predicted ultimate tensile strength $(224.45 \mathrm{MPa})$, the experimental result was lower than that achieved by MEs and, in turn, the relative percent error was equal to $1.65 \%$. As far as UE is concerned, a greater difference emerged between predicted and actual values, likely due to the lower fitting accuracy of the employed metamodel. The metaheuristic approach yielded again a set of parameters able to assure the highest UE of $11.75 \%$, though the relative percent error, equal to $4.30 \%$, was significantly higher than that assured by the DF-related parameters, equal to $1.89 \%$. In conclusion, numerical results shown in Figure 12 confirm the adequacy of the optimization approach based on the metaheuristic algorithms, which represent a valid and performing alternative to the regular optimizer embedded within the statistics commercial package.

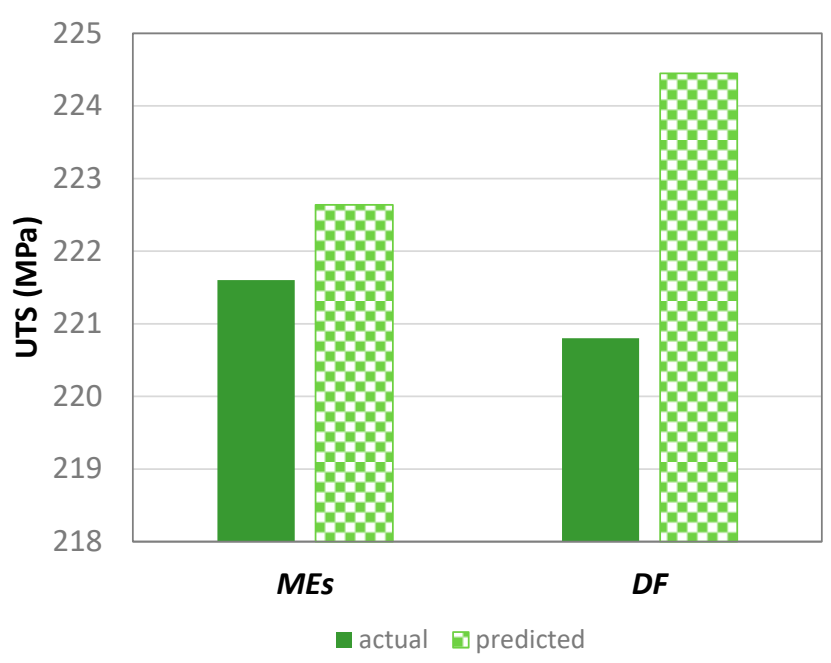

(a)

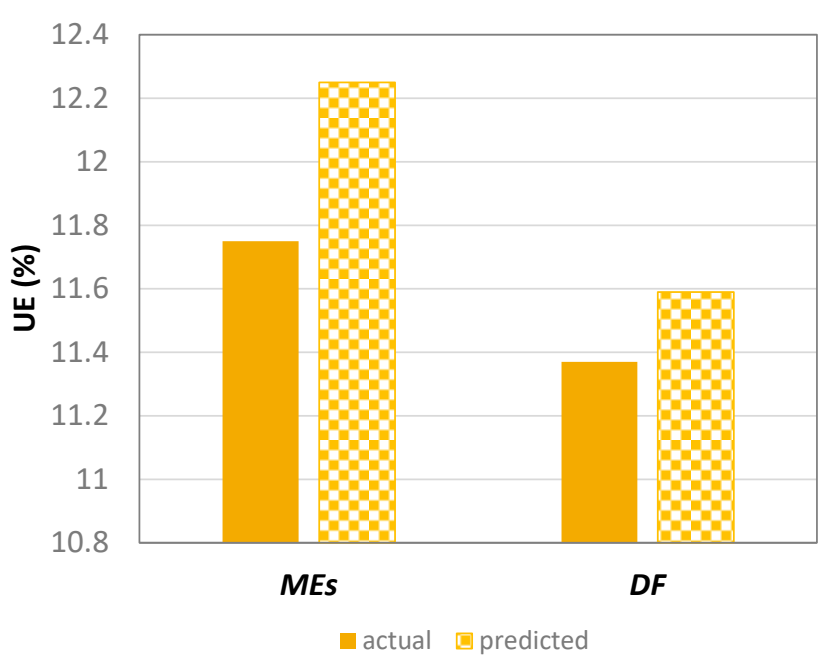

(b)

Figure 12. Comparison between the results obtained by the metaheuristic algorithms and those given from the desirability function by Minitab 17 in terms of: (a) UTS and (b) UE values.

\section{Conclusions}

In this paper, the optimization of process parameters concerning with the friction stir welding process of AA6082-T6 aluminum alloy was carried out. The following main conclusions could be discussed: 
- Two second order empirical formula to predict both UTS and UE on the base of tool plunging, rotational and welding speed process parameters were developed. The aforementioned metamodels were formalized through a series of statistical methods, such as design of experiments, response surface, analysis of variance and regression analysis. An additional set of experimental tests was used to validate the provided mathematical models.

- Response surface methodology and three distinct metaheuristic algorithms were employed to select the best FSW parameters able to optimize the mechanical performances of the welded joint, in terms of UTS and UE. Differently from the most literary contributions, the optimal solution obtained by means of the RSM desirability function (DF) was compared with the optimal solutions achieved by the different MEs. The experimental analyses executed by employing the optimal process parameters confirmed effectiveness and reliability of the proposed MEs. Indeed, all MEs assure a smaller deviation between predicted and actual values in terms of optimal UTS. On the other hand, the actual UE achieved by using the ME-related process parameters was higher than that corresponding to the DF method, which, in turn, assures a smaller deviation with respect to the predicted output.

- The robustness of the proposed metamodels and the effectiveness of the tested metaheuristic algorithms allowed identifying the best process parameters in terms of TP, $\omega$ and $\mathrm{v}$ to be adopted for improving the mechanical properties of friction stir welded joint in the AA6082-T6 aluminum alloy.

As for future research, some interesting steps could regard the implementation of different modeling techniques, the investigation about the effect of adding process parameters on different responses such as hardness and corrosion rate on friction stir welded joints.

Author Contributions: Conceptualization, M.S., A.C., S.F. and A.F.; Data curation, M.S.; Formal analysis, M.S. and A.C.; Investigation, M.S.; Methodology, A.C.; Project administration, A.F.; Supervision, S.F.; Writing-original draft, M.S. and A.C.; Writing-review and editing, A.F. and S.F. All authors have read and agreed to the published version of the manuscript.

Funding: The author(s) received no financial support for the research, authorship, and/or publication of this article.

Institutional Review Board Statement: Not applicable.

Informed Consent Statement: Not applicable.

Data Availability Statement: The data presented in this study are available on request from the corresponding author.

Acknowledgments: The authors wish to thank Massimiliano Pieralisi and Luciano Greco for their support in carrying out the experimental tests.

Conflicts of Interest: The authors declare no conflict of interest.

\begin{tabular}{ll}
\multicolumn{2}{l}{ Abbreviations } \\
ACO & ant-colony optimization \\
ANFIS & adaptive neuro-fuzzy inference system \\
ANN & artificial neural network \\
BM & base material \\
CRD & completely randomized design \\
D & shoulder diameter \\
DE & differential evolution \\
DF & desirability function \\
DOE & design of experiment \\
F & axial force \\
FLT & fuzzy logic technique \\
FSW & friction stir welding \\
GA & genetic algorithm
\end{tabular}




\begin{tabular}{|c|c|}
\hline GRG & reduced gradient method \\
\hline $\mathrm{H}$ & tool hardness \\
\hline HJ-PS & Hooke and Jeeves pattern search \\
\hline HS & harmony search \\
\hline HT & heat input \\
\hline Max_G & maximum number of generations \\
\hline ME & metaheuristic algorithms \\
\hline NLR & non-linear regression \\
\hline NP & population size \\
\hline $\mathrm{P}$ & pin diameter \\
\hline PSO & particle swarm optimization \\
\hline $\mathrm{R}$ & reinforcement \\
\hline RSM & response surface methodology \\
\hline R-sq & determination coefficient \\
\hline$R^{2}$-adj & adjusted determination coefficient \\
\hline SA & simulated annealing \\
\hline S-values & sensitivity values \\
\hline $\mathrm{T}$ & tool tilt angle \\
\hline $\mathrm{T}_{\mathrm{m}}$ & maximum temperature \\
\hline $\mathrm{T}_{\mathrm{p}}$ & tool profile \\
\hline $\mathrm{TP}$ & tool plunging \\
\hline UE & ultimate elongation \\
\hline UTS & ultimate tensile strength \\
\hline YS & yield strength \\
\hline $\mathrm{v}$ & welding speed \\
\hline$\Delta \_U E$ & relative error in percentage for each test over ultimate elongation \\
\hline $\begin{array}{l}\Delta \_U T S \\
\omega\end{array}$ & $\begin{array}{l}\text { relative error in percentage for each test over ultimate tensile strength } \\
\text { rotational speed }\end{array}$ \\
\hline
\end{tabular}

\section{References}

1. Verma, S.; Misra, J.P. A Critical Review of Friction Stir Welding Process. In DAAAM International Scientific Book; Katalinic, B., Ed.; DAAAM International: Vienna, Austria, 2015; pp. 249-266. ISBN 9783902734051.

2. Meshram, S.D.; Paradkar, A.G.; Reddy, G.M.; Pandey, S. Friction stir welding: An alternative to fusion welding for better stress corrosion cracking resistance of maraging steel. J. Manuf. Process. 2017. [CrossRef]

3. Bevilacqua, M.; Ciarapica, F.E.; Forcellese, A.; Simoncini, M. Comparison among the environmental impact of solid state and fusion welding processes in joining an aluminium alloy. Proc. Inst. Mech. Eng. Part B J. Eng. Manuf. 2019. [CrossRef]

4. Dialami, N.; Chiumenti, M.; Cervera, M.; Agelet de Saracibar, C.; Ponthot, J.P. Material flow visualization in friction stir welding via particle tracing. Int. J. Mater. Form. 2015, 8, 167-181. [CrossRef]

5. Lertora, E.; Gambaro, C. AA8090 Al-Li Alloy FSW parameters to minimize defects and increase fatigue life. Int. J. Mater. Form. 2010, 3, 1003-1006. [CrossRef]

6. Adamowski, J.; Gambaro, C.; Lertora, E.; Ponte, M.; Szkodo, M. Analysis of FSW welds made of aluminium alloy AW6082-T6. Arch. Mater. Sci. Eng. 2007, 28, 453-460.

7. Du, Z.; Chen, H.C.; Tan, M.J.; Bi, G.; Chua, C.K. Investigation of porosity reduction, microstructure and mechanical properties for joining of selective laser melting fabricated aluminium composite via friction stir welding. J. Manuf. Process. 2018. [CrossRef]

8. Simoncini, M.; Forcellese, A. Effect of the welding parameters and tool configuration on micro- and macro-mechanical properties of similar and dissimilar FSWed joints in AA5754 and AZ31 thin sheets. Mater. Des. 2012, 41. [CrossRef]

9. Forcellese, A.; Martarelli, M.; Simoncini, M. Effect of process parameters on vertical forces and temperatures developed during friction stir welding of magnesium alloys. Int. J. Adv. Manuf. Technol. 2016, 85. [CrossRef]

10. Bruni, C.; Buffa, G.; Fratini, L.; Simoncini, M. Friction stir welding of magnesium alloys under different process parameters. Mater. Sci. Forum 2010, 638-642, 3954-3959. [CrossRef]

11. Box, G.; Wilson, K. On the Experimental Attainment of Optimum Conditions. J. R. Stat. Soc. Ser. B 1951, 13, 1-45. [CrossRef]

12. Lakshminarayanan, A.K.; Balasubramanian, V. Comparison of RSM with ANN in predicting tensile strength of friction stir welded AA7039 aluminium alloy joints. Trans. Nonferrous Met. Soc. China 2009, 19, 9-18. [CrossRef]

13. Kamal Babu, K.; Panneerselvam, K.; Sathiya, P.; Noorul Haq, A.; Sundarrajan, S.; Mastanaiah, P.; Srinivasa Murthy, C.V. Parameter optimization of friction stir welding of cryorolled AA2219 alloy using artificial neural network modeling with genetic algorithm. Int. J. Adv. Manuf. Technol. 2018, 94, 3117-3129. [CrossRef]

14. Shehabeldeen, T.A.; Elaziz, M.A.; Elsheikh, A.H.; Hassan, O.F.; Yin, Y.; Ji, X.; Shen, X.; Zhou, J. A Novel Method for Predicting Tensile Strength of Friction Stir Welded AA6061 Aluminium Alloy Joints Based on Hybrid Random Vector Functional Link and Henry Gas Solubility Optimization. IEEE Access 2020, 8, 79896-79907. [CrossRef] 
15. Shojaeefard, M.H.; Behnagh, R.A.; Akbari, M.; Givi, M.K.B.; Farhani, F. Modelling and pareto optimization of mechanical properties of friction stir welded AA7075/AA5083 butt joints using neural network and particle swarm algorithm. Mater. Des. 2013. [CrossRef]

16. Elaziz, M.A.; Shehabeldeen, T.A.; Elsheikh, A.H.; Zhou, J.; Ewees, A.A.; Al-Qaness, M.A.A. Utilization of random vector functional link integrated with marine predators algorithm for tensile behavior prediction of dissimilar friction stir welded aluminum alloy joints. J. Mater. Res. Technol. 2020, 9, 11370-11381. [CrossRef]

17. Babajanzade Roshan, S.; Behboodi Jooibari, M.; Teimouri, R.; Asgharzadeh-Ahmadi, G.; Falahati-Naghibi, M.; Sohrabpoor, H. Optimization of friction stir welding process of AA7075 aluminum alloy to achieve desirable mechanical properties using ANFIS models and simulated annealing algorithm. Int. J. Adv. Manuf. Technol. 2013, 69, 1803-1818. [CrossRef]

18. Dewan, M.W.; Huggett, D.J.; Warren Liao, T.; Wahab, M.A.; Okeil, A.M. Prediction of tensile strength of friction stir weld joints with adaptive neuro-fuzzy inference system (ANFIS) and neural network. Mater. Des. 2016. [CrossRef]

19. Shehabeldeen, T.A.; Elaziz, M.A.; Elsheikh, A.H.; Zhou, J. Modeling of friction stir welding process using adaptive neuro-fuzzy inference system integrated with harris hawks optimizer. J. Mater. Res. Technol. 2019, 8, 5882-5892. [CrossRef]

20. Shanavas, S.; Dhas, J.E.R. Quality Prediction of Friction Stir Weld Joints on AA5052 H32 Aluminium Alloy Using Fuzzy Logic Technique. Mater. Today Proc. 2018, 5, 12124-12132. [CrossRef]

21. Shanmuga Sundaram, N.; Murugan, N. Tensile behavior of dissimilar friction stir welded joints of aluminium alloys. Mater. Des. 2010, 31, 4184-4193. [CrossRef]

22. Elatharasan, G.; Kumar, V.S.S. Modelling and optimization of friction stir welding parameters for dissimilar aluminium alloys using RSM. Procedia Eng. 2012, 38, 3477-3481. [CrossRef]

23. Padmanaban, R.; Vignesh, R.V.; Povendhan, A.P.; Balakumharen, A.P. Optimizing the tensile strength of friction stir welded dissimilar aluminium alloy joints using particle swarm optimization. Mater. Today Proc. 2018, 5, 24820-24826. [CrossRef]

24. Palanivel, R.; Laubscher, R.F.; Vigneshwaran, S.; Dinaharan, I. Prediction and optimization of the mechanical properties of dissimilar friction stir welding of aluminum alloys using design of experiments. Proc. Inst. Mech. Eng. Part B J. Eng. Manuf. 2018, 232, 1384-1394. [CrossRef]

25. Elangovan, K.; Balasubramanian, V.; Babu, S. Developing an empirical relationship to predict tensile strength of friction stir welded AA2219 aluminum alloy. J. Mater. Eng. Perform. 2008, 17, 820-830. [CrossRef]

26. Elangovan, K.; Balasubramanian, V.; Babu, S. Predicting tensile strength of friction stir welded AA6061 aluminium alloy joints by a mathematical model. Mater. Des. 2009, 30, 188-193. [CrossRef]

27. Elatharasan, G.; Kumar, V.S.S. An experimental analysis and optimization of process parameter on friction stir welding of AA 6061-T6 aluminum alloy using RSM. Procedia Eng. 2013, 64, 1227-1234. [CrossRef]

28. Heidarzadeh, A.; Khodaverdizadeh, H.; Mahmoudi, A.; Nazari, E. Tensile behavior of friction stir welded AA 6061-T4 aluminum alloy joints. Mater. Des. 2012, 37, 166-173. [CrossRef]

29. Kalaiselvan, K.; Murugan, N. Role of friction stir welding parameters on tensile strength of AA6061-B4C composite joints. Trans. Nonferrous Met. Soc. China 2013, 23, 616-624. [CrossRef]

30. Palanivel, R.; Mathews, P.K.; Murugan, N. Development of mathematical model to predict the mechanical properties of friction stir welded AA6351 aluminum alloy Engineering Science and Technology Review. J. Eng. Sci. Technol. Rev. 2011, 4, 25-31. [CrossRef]

31. Rajakumar, S.; Balasubramanian, V. Establishing relationships between mechanical properties of aluminium alloys and optimised friction stir welding process parameters. Mater. Des. 2012, 40, 17-35. [CrossRef]

32. Rajakumar, S.; Balasubramanian, V. Predicting grain size and tensile strength of friction stir welded joints of AA7075-T6 aluminium alloy. Mater. Manuf. Process. 2012, 27, 78-83. [CrossRef]

33. Babu, N.; Karunakaran, N.; Balasubramanian, V. A study to estimate the tensile strength of friction stir welded AA 5059 aluminium alloy joints. Int. J. Adv. Manuf. Technol. 2017, 93, 1-9. [CrossRef]

34. Rajakumar, S.; Muralidharan, C.; Balasubramanian, V. Predicting tensile strength, hardness and corrosion rate of friction stir welded AA6061-T6 aluminium alloy joints. Mater. Des. 2011, 32, 2878-2890. [CrossRef]

35. Elangovan, K.; Balasubramanian, V.; Babu, S.C.; Balasubramanian, M. Optimising Friction Stir Welding parameters to maximise tensile strength of AA6061 aluminium alloy joints. Int. J. Manuf. Res. 2008, 3, 321-334. [CrossRef]

36. Ghaffarpour, M.; Dariani, B.M.; Hossein Kokabi, A.; Razani, N.A. Friction stir welding parameters optimization of heterogeneous tailored welded blank sheets of aluminium alloys 6061 and 5083 using response surface methodology. Proc. Inst. Mech. Eng. Part B J. Eng. Manuf. 2012, 226, 2013-2022. [CrossRef]

37. Boulahem, K.; Ben Salem, S.; Bessrour, J. Prediction model of ultimate tensile strength and investigation on microstructural characterization of friction stir welded AA2024-T3. Int. J. Adv. Manuf. Technol. 2018, 95, 1473-1486. [CrossRef]

38. Safeen, W.; Hussain, S.; Wasim, A.; Jahanzaib, M.; Aziz, H.; Abdalla, H. Predicting the tensile strength, impact toughness, and hardness of friction stir-welded AA6061-T6 using response surface methodology. Int. J. Adv. Manuf. Technol. 2016, 87, 1765-1781. [CrossRef]

39. Liao, T.W.; Daftardar, S. Model based optimisation of friction stir welding processes. Sci. Technol. Weld. Join. 2009, 14, 426-435. [CrossRef]

40. Farzadi, A.; Bahmani, M.; Haghshenas, D.F. Optimization of Operational Parameters in Friction Stir Welding of AA7075-T6 Aluminum Alloy Using Response Surface Method. Arab. J. Sci. Eng. 2017, 42, 4905-4916. [CrossRef] 
41. Rajakumar, S.; Muralidharan, C.; Balasubramanian, V. Optimization of the friction-stir-welding process and tool parameters to attain a maximum tensile strength of AA7075-T6 aluminium alloy. Proc. Inst. Mech. Eng. Part B J. Eng. Manuf. 2010, 224, 1175-1191. [CrossRef]

42. Ouyang, H.B.; Gao, L.Q.; Li, S.; Kong, X.Y.; Wang, Q.; Zou, D.X. Improved Harmony Search Algorithm: LHS. Appl. Soft Comput. J. 2017, 53, 133-167. [CrossRef]

43. Eberhart, R.; Kennedy, J. A new optimizer using particle swarm theory. In Proceedings of the MHS'95. Proceedings of the Sixth International Symposium on Micro Machine and Human Science, Nagoya, Japan, 4-6 October 1995; pp. 39-43.

44. Storn, R.; Price, K. Differential Evolution-A Simple and Efficient Heuristic for global Optimization over Continuous Spaces. J. Glob. Optim. 1997, 11, 341-359. [CrossRef]

45. Geem, Z.W.; Kim, J.H.; Loganathan, G.V. A New Heuristic Optimization Algorithm: Harmony Search. Simulation 2001, 76, 60-68. [CrossRef]

46. Forcellese, A.; Simoncini, M.; Casalino, G. Influence of process parameters on the vertical forces generated during friction stir welding of AA6082-T6 and on the mechanical properties of the joints. Metals 2017, 7, 350. [CrossRef]

47. Rajendran, C.; Srinivasan, K.; Balasubramanian, V.; Balaji, H.; Selvaraj, P. Effect of tool tilt angle on strength and microstructural characteristics of friction stir welded lap joints of AA2014-T6 aluminum alloy. Trans. Nonferrous Met. Soc. China 2019, 29, 1824-1835. [CrossRef]

48. Chen, Y.; Liu, H.; Feng, J. Friction stir welding characteristics of different heat-treated-state 2219 aluminum alloy plates. Mater. Sci. Eng. A 2006, 420, 21-25. [CrossRef]

49. Barlas, Z.; Ozsarac, U. Effects of FSW Parameters on Joint Properties of AlMg3 Alloy. Weld. J. 2012, 91, 16s-22s.

50. Zadpoor, A.A.; Sinke, J.; Benedictus, R. The effects of friction stir welding on the mechanical properties and microstructure of 7000 series aluminium tailor-welded blanks. Int. J. Mater. Form. 2008, 1, 1311-1314. [CrossRef]

51. Montgomery, D.C. Design and Analysis of Experiments; John Wiley and Sons, Inc.: Hoboken, NJ, USA, 2012.

52. Lukács, J.; Meilinger, Á.; Pósalaky, D. High cycle fatigue and fatigue crack propagation design curves for 5754-H22 and 6082-T6 aluminium alloys and their friction stir welded joints. Weld. World 2018, 62, 737-749. [CrossRef]

53. Moreira, P.M.G.P.; de Jesus, A.M.P.; Ribeiro, A.S.; de Castro, P.M.S.T. Fatigue crack growth in friction stir welds of $6082-T 6$ and 6061-T6 aluminium alloys: A comparison. Theor. Appl. Fract. Mech. 2008, 50, 81-91. [CrossRef]

54. Cochran, W.G.; Cox, G.M. Experimental Designs; John Wiley and Sons: Hoboken, NJ, USA, 1957.

55. Mishra, R.S.; Ma, Z.Y. Friction Stir Welding and Processing II. Mater. Sci. Eng. R. Rep. 2014, 50, 1-78. [CrossRef]

56. Cabibbo, M.; Forcellese, A.; Simoncini, M.; Pieralisi, M.; Ciccarelli, D. Effect of welding motion and pre-/post-annealing of friction stir welded AA5754 joints. Mater. Des. 2016, 93. [CrossRef]

57. Bevilacqua, M.; Ciarapica, F.E.; D'Orazio, A.; Forcellese, A.; Simoncini, M. Sustainability Analysis of Friction Stir Welding of AA5754 Sheets. Procedia CIRP 2017, 62, 529-534. [CrossRef]

58. Simoncini, M.; Cabibbo, M.; Forcellese, A. Development of double-side friction stir welding to improve post-welding formability of joints in AA6082 aluminium alloy. Proc. Inst. Mech. Eng. Part B J. Eng. Manuf. 2016, 230. [CrossRef]

59. Trueba, L.; Torres, M.A.; Johannes, L.B.; Rybicki, D. Process optimization in the self-reacting friction stir welding of aluminum 6061-T6. Int. J. Mater. Form. 2018, 11, 559-570. [CrossRef]

60. Costa, M.I.; Rodrigues, D.M.; Leitão, C. Analysis of AA 6082-T6 welds strength mismatch: Stress versus hardness relationships. Int. J. Adv. Manuf. Technol. 2015, 79, 719-727. [CrossRef]

61. Cabibbo, M.; Forcellese, A.; Santecchia, E.; Paoletti, C.; Spigarelli, S.; Simoncini, M. New approaches to friction stir welding of aluminum light-alloys. Metals 2020, 10, 233. [CrossRef]

62. Verma, S.; Gupta, M.; Misra, J.P. Effect of pin-profiles on thermal cycle, mechanical and metallurgical properties of friction stir-welded aviation-grade aluminum alloy. Proc. Inst. Mech. Eng. Part B J. Eng. Manuf. 2019, 233, 2183-2195. [CrossRef]

63. Forcellese, A.; Simoncini, M. High-speed deformation of pinless fswed thin sheets in aa6082 alloy. Metals 2020, 10, 15. [CrossRef] 